\title{
Hitler und die Sinngebung der deutschen Geschichte
}

Essay über eine soziologische Deutung

\section{Hans-Günter Zmarzlik zum 65. Geburtstag}

Wenn einem im Jahre 1977 gedruckten Bericht und Entwurf des Themas »Modernisierungstheorie und Nationalsozialismus« zehn Jahre später noch keine systematische Darstellung unter diesem Blickwinkel gefolgt ist ${ }^{1}$, nicht einmal neuere Monographien mit einer eindeutig modernisierungstheoretischen Fragestellung sich an zentrale Probleme der historischen Erforschung des NS-Regimes heranwagen ${ }^{2}$, besteht Anlaß, das Thema für erledigt zu halten. Doch so ist es nicht. Der Einfluß modernisierungstheoretischer Thesen steht vielmehr in geradezu umgekehrt proportionalem Verhältnis zu ihrer Solidität. So schrieb darüber fast jeder, der sich anläßlich des 50jährigen Jubiläums der nationalsozialistischen Machtergreifung äußerte, oftmals in gelinde gesagt dunklen Formulierungen, aber nur die allerwenigsten Stellungnahmen ließen gegenüber der Verwendung des Revolutionsbegriffs Skepsis erkennen ${ }^{3}$. Skepsis auch nicht gegenüber der hiermit nicht nur in begrifflichem Zusammenhang stehenden Interpretation der nationalsozialistischen Herrschaft als zwar weitgehend unbeabsichtigtem, dennoch praktiziertem Durchbruch Deutschlands zur Moderne, was immer im einzelnen darunter verstanden werden mag. Und ein Quäntchen mehr an Mißtrauen gegenüber den geistreichen Versuchen, einerseits der in gewissem Sinn erstaunlichen Stabilität der westdeutschen Demokratie näher zu kommen (die Existenz der DDR bleibt nämlich überwiegend unberücksichtigt, würde auch nicht ins Konzept passen), andererseits das Dritte Reich unter Berücksichtigung des Resultats einer bis dato »undurchschauten Logik der deutschen Geschichte « ${ }^{4}$ zuzuordnen, war und ist (leider) durchaus wünschenswert, denn wo immer die Forschung konkrete Anhaltspunkte für eine Revolution zwischen 1933 und 1945 gesucht hat, ergab sich entweder Fehlanzeige, oder stieß man auf eine höchst ambivalente Gemengelage ${ }^{5}$.

Daher versucht der letzte Teil dieser Abhandlung, den Gründen des nicht recht verdienten Einflusses der Revolutions-These nachzuspüren. Nicht in der Absicht, diesen Aspekt erschöpfend zu behandeln (wie die marxistische Kritik es sich vorbehält), sondern um einige womöglich interessante Vermutungen über eine geistesgeschichtliche Grundhaltung beizusteuern, die dem Nationalsozialismus die gar nicht begrüßte Teilhabe am Projekt der Moderne sichert. Doch sollen die Leistungen dieses, man könnte sagen: 68er Konkurrenzparadigmas zum marxistischen Ansatz nicht unterschlagen werden. Diese Leistungen liegen 1. auf dem Gebiet der Erforschung von Ursachen des Nationalsozialismus hinsichtlich angenommener Kontinuitäten der deutschen Geschichte, die von einem leicht idealisierten und etwas geglätteten Königsweg der Entwicklung westlicher Demokratien abweichen ${ }^{6}$. Und ohne Zweifel ist das Konkurrenzparadigma - nicht zuletzt infolge der provozierten Kritik - 2. in der Lage, auf längere Sicht neue Einsichten in die Natur des NS-Regimes zu eröffnen, deutlich und bisweilen überdeutlich jenseits der bis in die 60er Jahre vorherrschenden Totalitarismustheorie, wenn auch nicht ohne Rückgriff auf einige ihrer konstituierenden Elemente ${ }^{7}$. Die beiden ersten Teile der vorliegenden Abhandlung sind freilich weniger den Vorzügen als vielmehr offenbaren Fehldeutungen der Revolutions-These gewidmet. Der dritte, über Italien, hat den Charakter eines methodischen Hinweises, vielleicht auf die bekömmliche Nicht-Rezeption eines Paradigmas. Hat doch die italienische Ge- 
schichtswissenschaft das Thema »Italien und die Modernisierung « ebensowenig aufgegriffen wie seinerzeit die Totalitarismustheorie.

$\mathrm{Da}$, wie gesagt, eine systematische Interpretation des Nationalsozialismus entlang einer modernisierungstheoretischen Fragestellung nicht vorliegt, sind auch die folgenden Ausführungen einigermaßen verwirrend in Hinsicht auf die Vielzahl der angesprochenen Probleme geraten. Jedoch soll versucht werden, einige durchaus heterogene Ergebnisse, so wie sie vorliegen, mit Hilfe weiter gespannter, zum Teil vergleichender Betrachtung auf einen praktikablen Nenner zu bringen, mindestens insoweit, daß scheinbar eindeutige Befunde etwa aus dem sozialen Bereich ${ }^{8}$ nicht ebenso eindeutigen aus dem politischen oder kulturellen gegenüberstehen oder einander gar in irgendeiner Form entsprechen.

I.

Samuel P. Huntington definierte 1968 Revolution als "rapiden, fundamentalen und gewaltsamen inneren Wandel in den herrschenden Werten und Mythen einer Gesellschaft, in ihren politischen Institutionen, ihrer sozialen Struktur, ihrer Führung und den Aktivitäten der Regierung «. Er suchte so Revolutionen zu unterscheiden von Aufruhr, Rebellion, Revolte, Staatsstreich und Unabhängigkeitskrieg. Als das politische Wesen einer Revolution sah er die rasche Ausbreitung politischen Bewußtseins und die ebenso rasche Mobilisierung neuer Gruppen im politischen Raum an, beides in einem Tempo, »das es existierenden politischen Institutionen unmöglich macht, sie zu assimilieren«. Eine vollständige Revolution aber ist darüber hinaus durch eine zweite Phase gekennzeichnet: »die Schaffung und Institutionalisierung einer neuen politischen Ordnung “, wobei das Ausmaß des Revolutionären am Umfang und am Tempo der politischen Partizipation (an diesem neuen System) zu messen sei, das Maß des Erfolges einer Revolution sich aus der Autorität und Stabilität derjenigen Institutionen ergebe, die sie hervorgebracht habe 9 .

Das Prädikat Revolution ist also, kurz gesagt, nicht billig zu haben. Selbst wer bereit ist, Abstriche vom Konzept zu machen, ețwa den Gehalt der Variablen auf ein gewisses Mindestmaß zurechtzustutzen und damit zugleich die Art der Revolution zu spezifizieren (als soziale, politische oder Kulturrevolution beispielsweise), oder dafür plädiert, nicht von einem totalen Systemwandel auszugehen, sondern nur einzelne Indikatoren zu überprüfen ${ }^{10}$, oder auch es mit der Rapidität nicht so genau nehmen möchte, zumal das im hier zu diskutierenden Fall weder nötig noch möglich ist, der wird nicht ohne ein gewisses Erstaunen zur Kenntnis nehmen, welch reduzierter Revolutionsbegriff neuerdings von Horst Möller - um den elaboriertesten und didaktisch wertvollsten Aufsatz herauszugreifen - der nationalsozialistischen Machtergreifung unterlegt wird ${ }^{11}$. Nicht daß aus Möllers Ausführungen schlüssig hervorginge, ob der nationalsozialistischen Herrschaft tatsächlich ein revolutionärer Charakter zuerkannt wird, auch bleibt rätselhaft, welcher Machart diese - wenn zutreffend - Revolution gewesen sein soll. Möller überprüft nur Wellenlänge, Verfassungswidrigkeit und Pathos ${ }^{12}$.

Es geht hier nicht, auch dies pflegt die marxistische Kritik sich ja vorzubehalten, um die Schaffung einer Basis für Sprachzensur, wie Willi Paul Adams einmal ziemlich pauschal unterstellt hat ${ }^{13}$, sondern um Aufnahme eines Frage- und Forschungsimpulses in Form eines zeitgenössisch zweifellos wertend-propagandistisch benutzten Begriffs, der gleichwohl als analytisch-sozialwissenschaftliche Kategorie oder Begriffskomplex behandelt zu werden verdient. 
Möller geht vom unvollständigen Charakter der Revolution 1918/19 aus, was hier nicht interessieren soll und wohl auch kaum umstritten ist. Er begreift die nationalsozialistische Machtergreifung 1933/34 als Beginn einer Revolution, die 1945 schließlich das erbrachte, was 1918/19 noch fehlte: soziale Umschichtung und damit quasi soziale Demokratisierung der Führungsschichten, sowohl was soziale Herkunft, Bildungsstand, berufliche Laufbahn, also die Felder Status und Lebensalter im sozialen Gefüge anbelangt ${ }^{14}$. Die Machtergreifung sei demgemäß nach Intention, Verlauf und Wirkung revolutionär gewesen ${ }^{15}$, konkreter: diese Revolution zerstörte das gültige Rechtssystem, baute in destruktiven Akten eine der Zielsetzung nach totalitäre Diktatur auf, brachte eine NS-Herrschaftselite in »die entscheidenden Führungsstellen « und löste damit »in einem erheblichen Ausmaß die Weimarer Führungsschichten sowie die vom Kaiserreich übernommenen Machteliten ab. Die NS-Revolution brachte zustande, daß die an sich reaktionären Ideologeme des Nationalsozialismus und der totale Anspruch seiner mit modernsten Mitteln arbeitenden Diktatur »über weite Strecken zur Lebensrealität des NS-Staates wurden “ ${ }^{16}$.

Es fällt auf, daß die hier verwandten Begriffe und Definitionen streckenweise durchaus unpräzise sind. Zu den "entscheidenden Führungsstellen " gehören die in Industrie und Wehrmacht (letztere ausdrücklich) nicht, immerhin zwei weithin anerkannte Säulen des Regimes; unter Rechtssystem versteht Möller offenbar einseitig das Verfassungsrecht (und beachtet dabei weder, daß hier auf dem Verordnungs- und Anordnungswege vieles unterlaufen, wenig aber beseitigt wurde und werden mußte, noch, daß es in anderen Bereichen des Rechtssystems ebenso finster aussah). In wenigen Worten: die Interpretation wird der bemerkenswert atemlosen Kurzbeinigkeit nationalsozialistischer Veränderungsversuche kaum gerecht. Weniger noch der zuvor zitierten Revolutions-Definition. Auch mit der Zurückhaltung, die Theodor Schieder noch 1972 in einem Lexikonartikel dem vergleichsweise ausführlich gewürdigten Nationalsozialismus gegenüber walten ließ ${ }^{17}$, hat das kaum noch etwas gemein. Wer sich freut, wenn Möller ankündigt, überprüfen zu wollen, ob die NS-Machtergreifung nach Zielsetzung, Verlauf und Wirkung "eine Revolution im Sinne historisch-politischer Revolutionstheorien " war ${ }^{18}$, wird enttäuscht, denn es werden ausschließlich zeitgenössische Theoretiker zu Rate gezogen, Ernst Troeltsch, Friedrich Meinecke, Paul Herre, Theodor Geiger und Leopold v. Wiese ${ }^{19}$. Hieraus wird geschlossen, die Machtergreifung sei nicht, wie seinerzeit vorgeschützt, legal verlaufen, was ja auch bereits seit den frühen $60 \mathrm{er}$ Jahren allgemein anerkannt wird ${ }^{20}$, ferner die Grunderkenntnis gewonnen, bei Revolutionen handle es sich um "langestreckte Prozesse, in denen destruktive und konstruktive Geschehnisserien sich gegenseitig bedingen « ${ }^{21}$. Das läßt sich aber nicht auf eine angebliche Revolution von 1919 bis 1945 mit Kulminationspunkt 1933 oder, alternativ, eine NS-Revolution 1933 beziehungsweise eine soziale Revolution 1933 bis 1945 anwenden, ganz schlicht gesprochen mangels nationalsozialistischer Aufbauleistung, wie man ebenso zeitgemäß formulieren könnte ${ }^{22}$. Eine politische Revolution von notwendig begrenzter Dauer (angesichts der Endziele des „Führers») ließe der Vorgang sich durchaus nennen, doch Möller hält die Frage, ob die NS-Revolution mit einem Wechsel der politischen Führungsschicht einherging und ob sie einen fundamentalen Strukturwandel der Gesellschaft bewirkt habe, »für die Verwendung des Revolutionsbegriffs nicht zwingend«, da man sonst »beispielsweise in bezug auf die [Revolution] von $1848 / 49$ « auch nicht von Revolution reden könne ${ }^{23}$. Die ist nun bekanntlich gescheitert, obgleich auch sie ihre Wirkungen hatte, nur nicht die einer sozialen Systemtransformation, und die hätte vermutlich auch ihr Erfolg nicht verbürgt.

Und die Frage ist zwingend, will man eine Revolution von Revolten, Staatsstreichen etc. unterscheiden. Weiterhin ist, wie Reinhart Koselleck dargelegt hat, die Unterscheidung zwischen politischen, sozialen und anderen Revolutionen seit dem vorigen 
Jahrhundert üblich, und die neuere Revolutionsforschung läßt auf keine Notwendigkeit schließen, diese sinnvolle Unterscheidung fallenzulassen ${ }^{24}$. Andererseits ist es möglich, eine Neuordnung des Verhältnisses von Staat und Gesellschaft als Revolution zu begreifen. Hierbei wäre zu fragen, ob diese Veränderung (Systemtransformation) einem langfristigen Trend oder einem punktuellen politischen Umbruch zuzuordnen ist, wobei Verfechter des Totalitarismus-Modells sich vermutlich für die zweite Möglichkeit entscheiden werden, weil dieses von tieferen Eingriffen des Staates (bzw. der Partei) in die Gesellschaft ausgeht, als die konkurrierenden Modelle. In diesem Fall bietet allerdings der NS-Staat nicht jene Systemstruktur, die Walter L. Bühl jüngst als zuträglichste für die revolutionäre beziehungsweise evolutionäre Systemtransformation analysiert hat ${ }^{25}$.

Um eine Revolution wiederum von sozialem Wandel zu unterscheiden, wäre ferner die Frage nach einem - möglicherweise sogar beabsichtigten und geplanten - Wandel der sozialen Beziehungen (und nicht nur des sozialen Gefüges) zu stellen sowie nach den Aufstiegschancen nicht nur im politischen und von politischen Organisationen direkt beeinflußten Bereich, beispielsweise anhand der Schulpolitik, oder die, ob neue politische Eliten etwa auf dem Wege über ein neues Schulsystem in das soziale System hineinplaciert oder nur zweite und dritte neue (politische) Elitensysteme geschaffen wurden. Wir werden darauf zurückkommen.

Richard Löwenthal bereichert mit seinem Einleitungsvortrag der internationalen Konferenz zur nationalsozialistischen Machtübernahme in Berlin die Diskussion um die Komponenten einer beabsichtigten Revolutionierung des europäischen Staatensystems, wenn nicht des Welt-Staatensystems, und einer rassistischen, bevölkerungspolitischen Revolution ${ }^{26}$. Ernst Nolte wiederum hat die letztgenannte Komponente unter Zuhilfenahme des älteren Nachweises Eugen Webers, daß die Norm der guten Revolution und der schlechten Konterrevolution ein Mythos ist, dazu genutzt, Hitler persönlich zum revolutionären Gegenrevolutionär zu erklären, da er ja durch Ausrottung der Juden Kapitalismus und Bolschewismus zugleich transzendieren wollte ${ }^{27}$. Damit ist die Frage zwar zum individuellen intellektuellen Problem herabgemindert, denn der Mord an den Juden hatte, wie vorauszusehen war, die wunschgemäß darüber hinausgehenden Folgen gesellschaftspolitischer Art nicht, aber die Revolutionierung des Staatensystems ist eine Tatsache, wenngleich statt des intendierten zwei- oder dreisäuligen ein bipolares System an die Stelle eines multipolaren trat. Fraglich ist, ob ungewöhnliche Manieren der deutschen Diplomatie und eine illusionäre Kriegspolitik unbedingt als Revolution bezeichnet werden müssen, oder ob das unter Karl Dietrich Brachers Verdikt von der Erhebung der Revolution zum Allerweltswort zu subsumieren ist ${ }^{28}$.

Die Machtergreifung als politische Revolution also (auch Löwenthal und Nolte verzichten auf dieses Adjektiv) und weitergehende Kriegsfolgen. Was aber erlebte Deutschland zwischen 1933 und 1945, außer einem Krieg: eine soziale Revolution, wie manche zu meinen scheinen, oder ein zwölfjähriges Festival der Einbildungskraft? Irgendwie frappierend ist am neuen Revolutionsmythos (wenn es einer ist), daß irgendein Erkenntnisfortschritt gegenüber der Auffassung von Joseph Goebbels aus dem Jahr 1933 nicht auszumachen ist ${ }^{29}$.

II.

Der, wie geschildert, problematische und etwas kurzschlüssige Gebrauch des Revolutionsbegriffs ist wohl nur - von Horst Möllers ausdrücklichem Verzicht einmal abgesehen - als Bezugnahme auf ungeprüfte modernisierungstheoretisch inspirierte Inter- 
pretationen des Dritten Reichs zu verstehen, in erster Linie auf Ralf Dahrendorfs überaus intelligente Versuche. Dabei war die These von der NS-Revolution ganz so »unverdrossen«, wie Volker Hentschel kürzlich meinte ${ }^{30}$, gar nicht kolportiert worden, ausgenommen vielleicht in der Literatur, die Hitler, den Nationalsozialismus und das Dritte Reich einem breiteren Publikum näherbringen wollte. Jedoch fast schlagartig mit dem schon erwähnten Jubiläum 1983 werden eben auch Beiträge in wissenschaftlichen Fachzeitschriften um die eher semantische als sachdienliche Variante der Revolution (statt Machtergreifung, -übernahme, Errichtung des NS-Regimes usw.) bereichert.

Es kann daher nicht schaden, so kurz wie möglich den Gehalt der soziologischen Modernisierungstheorien zu vergegenwärtigen. Die Komplexität des Vorgangs der Modernisierung wird aus einer Aufzählung von Merkmalen derselben ersichtlich, die Thomas Nipperdey zusammengetragen hat ${ }^{31}$. Sie umfaßt demographische, ökonomische, soziale, kulturelle und mentale Faktoren - insgesamt neununddreißig - die hier etwas beliebig und ohne Kennzeichnung gravierender Abhängigkeitsverhältnisse aneinandergereiht sind. Frühe Modernisierungstheorien ließen derart lakonische Listen gern in eine schlichte Dichotomie vormodern versus modern aufgehen, gingen von einem wie immer gearteten Durchbruch zur Moderne aus, der dann wieder eine relativ gleichgewichtige Entwicklung des industriellen, sozialen, politischen und mentalen Komplexes zu gewährleisten hatte, um spezifische Modernisierungskrisen - sprich: Spannungen und Widersprüche - zwischen den einzelnen Komplexen innerhalb des Prozesses zu vermeiden. Jüngere Theorien gehen dagegen durchaus von einer Koexistenz angenommener moderner und vormoderner Aspekte aus, sie messen dabei dem Moment der Koordinationsfähigkeit verschiedener Niveaus innerhalb der Gesellschaft größte Bedeutung bei ${ }^{32}$.

Die klassischen Beiträge der Modernisierungstheorie zur Deutung der deutschen Entwicklung sind weitestgehend noch dem ersten Typ der Theorie verpflichtet. Während ihre Thesen über die Ursachen des Nationalsozialismus - zur Zeit ihrer Entstehung noch jenseits der geistes- und politikgeschichtlichen Hauptströmungen der Geschichtswissenschaft angesiedelt - im Zug der durch sie in Gang gebrachten empirischen Forschung weitestgehend als abgesichert angesehen werden können, fast schon zu Gemeingut der Geschichtskenntnis abgesunken sind, scheinen die Ergebnisse der neueren und neuesten Forschung über das nationalsozialistische Regime den Revolutions-Thesen in höherem Maß zu widersprechen, als es das von den Autoren vorgelegte Material selbst tat.

\section{Ursachen des Nationalsozialismus:}

Nach Ralf Dahrendorf stellt die von ihm so genannte "Verwerfung traditional-autoritärer und modern-demokratischer Strukturen « der deutschen Gesellschaft im Gefolge einer "Revolution von oben « statt von unten das zentrale "Syndrom« dar, an dem diese Gesellschaft vom 19. bis in das 20. Jahrhundert hinein kränkelte. Ein rechtsextremes Übel, an sich nichts außergewöhnliches in westlichen Industriegesellschaften ${ }^{33}$, ließ sie in ernsthafte Schwierigkeiten geraten. Merkmale des "Syndroms" sind ein permanenter Mittelstand an der Stelle, wo gemessen am angloamerikanischen Idealtyp eine selbstbewußte und reformbereite Bourgeoisie hingehörte, ein verhinderter Kapitalismus, der erst in einem fast nicht mehr demokratiefähigen Alter auf die Welt kam, ein Staat, der anstelle der Wirtschaft den Ton angab, insgesamt eine Gesellschaft, die, indem sie einer irrealen Utopie der Konfliktlosigkeit anhing, gern jede Form von Unterdrückung jedweder Opposition in Kauf nahm, dann aber Konflikte auf nicht absehbare Zeit per Gesetz zu regeln suchte, eine Gesellschaft schließlich, die öffentliche Tugenden (und Laster ohnehin) den privaten unterzuordnen neigte, die sich lieber als $\mathrm{Ge}$ - 
meinschaft - in naturgegebener Ungleichheit - empfand, mit Intellektuellen, die entweder kritiklos oder unpolitisch (was dasselbe ist) oder aber Emigranten waren, eine Gesellschaft also, deren Strukturen und Werte quer zur Entwicklung einer demokratischen Ordnung standen ${ }^{34}$.

Dahrendorfs staatsbürgerkundliches Lehrbuch kontrastiert diese, in idealtypischer Hinsicht ja durchaus akzeptablen Symptomanalysen mit einem arg idealisierten Bild der englischen und amerikanischen Gesellschaften, blendet, offenbar aus Gründen der Anschaulichkeit, gegenläufige Entwicklungen beziehungsweise Symptome aus, wirkte aber gerade damit gewissermaßen schulebildend ${ }^{35}$. Ein eher am Rande liegendes Beispiel: In Ländern, behauptet Dahrendorf, die im Bereich der Jugenderziehung die Schule der Familie überordnen, weise diese letztere eine Tendenz auf, im Tönniesschen Sinn zur Gesellschaft, zur peer group, zum auf Vertragsbeziehungen beruhenden Sozialgebilde auf der Grundlage prinzipieller Gleichheit aller Mitglieder zu werden ${ }^{36}$. Nicht nur, daß diese Tendenz selbst am US-amerikanischen Beispiel allenfalls idealtypisch im Weberschen Sinn verstanden werden kann, solche Familien am häufigsten in den Nordstaaten der Westküste gefunden werden konnten, kaum jedoch im Mittelwesten und in den Südstaaten der 60er Jahre, ergo: daß dem also nicht ganz so ist. So kann es einfach nicht sein! Mag der amerikanische Umgangston bei der Ausübung innerfamiliärer Herrschaftsverhältnisse - wenn man so sagen darf - ein gepflegterer sein, die sekundäre Sozialisation dem Eingriff der Familie entzogen, weil überflüssig, geht es an die Reproduktion der Familie als solcher, sind die Besitzverhältnisse hier nicht anders geregelt als anderswo, erlangt auch der amerikanische Sohn gleichberechtigten Status erst als installierter Nachfolger des Vaters, von der Tochter ganz zu schweigen.

Adornos und anderer Studien zum mautoritären Charakter« werden denn auch wahrscheinlich in intimer Kenntnis der Vorarbeiten - umgehend geographisch falsch eingeordnet: hier sei »von Deutschland und dem Charakter der Deutschen die Rede ${ }^{37}$. An die hat Adorno sicher nicht zuletzt gedacht, aber die Studien beruhen ausschließlich auf amerikanischem Material.

Einflußreicher noch war die Studie von Barrington Moore, Jr., bis auf einen Punkt: sie hätte die soziologische Theorie um die Erkenntnis bereichern können, daß es nicht einen Königsweg und ansonsten nur Holzwege der politischen und sozialen Entwicklung zur Moderne gibt, sondern offensichtlich fast so viele Wege wie Fälle. Dem steht freilich nicht nur das Interesse der Soziologie an langfristig gültigen Gesetzmäßigkeiten entgegen. Moore stellt in seinen Studien stattgehabter und nicht stattgehabter Revolutionen von unten und von oben in England, Frankreich, den Vereinigten Staaten, China, Japan und Indien die Rolle des agrarischen Sektors in den Mittelpunkt des Ursachenkomplexes faschistischer Diktaturen, kommunistischer Diktaturen und Demokratien ${ }^{38}$. Dabei ist sein zentrales Problem die Berechnung der Kosten dieser unterschiedlichen Wege, vielleicht ein Grund, weshalb einer der kostenträchtigsten Fälle (Deutschland) nur nebenbei parallel zum näher untersuchten japanischen Fall behandelt wird.

Dennoch macht er in höherem Maß als Dahrendorf deutlich, warum in Deutschland eine rechtsextremistische Bewegung in weiten Kreisen der oberen Klassen Bündnispartner finden konnte: eine vom Adel unabhängig gewordene Monarchie vollführte eine kommerzielle Revolution von oben, die den Adel (anders als in England, wo dieser selbst tätig wurde) aussparte, welcher wiederum, nicht zuletzt mit Hilfe seiner Überrepräsentation im höheren Staatsdienst, die sogenannten vormodernen Zustände auf dem Lande weitgehend intakt zu halten suchte; eine von staatlicher Seite geförderte Bourgeoisie verblieb voll Zufriedenheit in Abhängigkeit von der Monarchie und übernahm (hier hat $\mathrm{m}$.W. auch die neueste Forschung noch keine klaren Unterschiede er- 
mittelt) in weiten Teilen das adlig-monarchisch-bürokratische Wertesystem, wie es ebenso auch der bürokratische Teil des Bürgertums tat ${ }^{39}$. Ohne zur Entstehung faschistischer Bewegungen allzu präzise Aussagen zu machen - das liegt wohl an der Wahl Japans als faschistischem Entwicklungstyp - läßt Moore sie und entscheidende Teile der schon beschriebenen Oberklassen auf der Basis eines plebejischen Antikapitalismus und mehr noch Autoritarismus zusammenfinden ${ }^{40}$. Fest steht inzwischen, daß in Deutschland nur ein Minderheitsvotum der industriellen Oberklasse für plebejischen Antikapitalismus wenigstens als Mittel zu einem bestimmten Zweck zustande kam, der nicht unbedingt ursprünglich agrarische Autoritarismus jedenfalls wichtiger war, und zweifelhaft ist auch, ob tatsächlich der Bauer, nicht viel eher der Arbeiter, den Bauern sicherlich nicht stillschweigend eingeschlossen, in reichlich romantisierter Gestalt Schlüsselfigur der nationalsozialistischen Ideologie wurde, wie Moore behauptet ${ }^{41}$. Prinzipiell also das gleiche Ergebnis wie bei Dahrendorf: Überbleibsel der vormodernen Welt (manchmal auch in leichter Übertreibung "archaisch« tituliert) verhalfen einer rechtsextremistischen Protestbewegung zum Durchbruch. Moore kann sich darauf beschränken, die japanische (deren Existenz übrigens nicht unumstritten ist) mit der deutschen faschistischen Bewegung dahingehend zu vergleichen, daß aus Gründen der unterschiedlichen Sozialstruktur im deutschen Fall der antikapitalistische Radikalismus nicht gleich stark ausgeprägt war ${ }^{42}$, und erspart sich gänzlich eine Erklärung der Tatsache, daß in Japan keine faschistische Bewegung an irgendwelche Macht gelangte, sondern Teile der Militärkaste eine Art faschistischer Ideologie goutierten, was alles in allem das Resultat eines autoritären Regimes mit den überkommenen stark repressiven Zügen hatte.

Es würde nicht weiterführen, hier auf weitere und detailliertere Studien einzugehen, die sich doch in demselben Rahmen bewegen ${ }^{43}$. Nur ein gewichtiger Einwand muß hervorgehoben werden. Thomas Nipperdey besteht darauf, daß nicht von einer einheitlichen Kontinuität der deutschen Geschichte gesprochen werden könne (Dahrendorfs Syndrom), sondern daß es sich um eine Mehrzahl durchaus unterschiedlicher Kontinuitäten handle. Ursachen der offensichtlich schwerwiegenden Modernisierungs- und Modernitätskrise sind dementsprechend weniger im Bereich der Regierungspolitik zu suchen als in dem Phänomen der Geschwindigkeit des Modernisierungsprozesses und in den dadurch zusammengedrängten Krisensituationen zu finden ${ }^{44}$. Damit ist die Unbefangenheit deutscher Eliten dem Nationalsozialismus gegenüber nicht aus der Welt ${ }^{45}$, und da Nipperdey nicht willens ist, den Modernisierungstheorien eine Hierarchie der relevanten Modernisierungsfaktoren abzugewinnen ${ }^{46}$, kann er allenfalls als partiell durch den von Hartmut Kaelble erhobenen Einwand widerlegt gelten, die Vorstellung von einer rapiden Industrialisierung Deutschlands sei, verglichen mit anderen europäischen Ländern - und eben nicht nur mit England -, ein Mythos ${ }^{47}$. Der intellektuelle und bürokratische Frühentwickler mit relativ spät einsetzenden Problemen der industriellen und sozialen Entwicklung sowie seiner nationalstaatlichen Integration aber bot dem Nationalsozialismus reichen Nährboden und Entwicklungsmöglichkeiten ${ }^{48}$.

\section{Das nationalsozialistische Regime:}

Da der Nationalsozialismus nun einmal eine ganz und gar unmoderne Ideologie pflegte, so meinte man lange Zeit, mußte er seine Anhänger, einmal an die Macht gelangt, wohl verraten, hinters Licht und sonstwohin geführt haben, denn keine der restaurativen Hoffnungen, die Angehörige des alten wie des neuen Mittelstandes, Bauern oder Naturschützer in ihn gesetzt hatten, gelangte im Dritten Reich zur Erfüllung. Zugleich gestanden schon zeitgenössische Beobachter ihm ein gewisses revolutionäres Potential $\mathrm{zu}$, obschon dieses nicht eindeutig in eine bestimmte Richtung zu weisen, sondern, und 
hier konnte auf große Teile einer eher gegenrevolutionär gestimmten Anhängerschaft verwiesen werden, zwischen Reaktion und Fortschritt zu oszillieren schien.

Franz Borkenau beispielsweise führte dieses Phänomen in einer äußerst funktionalistischen Betrachtung, erschienen im Februar 1933, darauf zurück, daß die deutsche Bourgeoisie in Anbetracht des Entwicklungsstandes der Industrie den Faschismus nicht an die Macht lassen könne, und gerade deren Anlehnung an die Restauration (sprich: Militär und Agrarier) der Dynamik des Nationalsozialismus förderlich sei, da die Erbitterung der von ihm zusammengefaßten Schichten sich ungehemmt auswirken kön$\mathrm{ne}^{49}$.

"Dynamik« und der von Borkenau verwandte Begriff der "Entwicklungsdiktatur» sind bis heute unterschiedlich ausgelegt und nicht wenig umstrittene Schlüsselbegriffe der Faschismusanalyse geblieben; nicht jede Diktatur kann schließlich eine Entwicklungsdiktatur sein, selbst wenn sie es will. Dahrendorf etwa machte die totalitäre Dynamik des Regimes dafür verantwortlich, die Vergangenheit der deutschen Sozialstruktur, wie sie im Kaiserreich von 1871 Gestalt angenommen hatte, »endgültig beseitigt « zu haben ${ }^{50}$. Die Probleme einer derartigen Diagnose liegen in der theoretischen Voraussetzung ebenso wie im empirisch nachweisbaren Detail.

Total mag der Machtanspruch des Regimes zwar gewesen sein, die totalitäre Durchdringung der deutschen Gesellschaft aber ließ, nach Ausweis neuerer Regional- und Lokalstudien insbesondere, durchaus zu wünschen übrig. Der massive Einbruch politischer Öffentlichkeit in die Privatsphäre auf der einen, der Rückzug in beziehungsweise das Beharren auf privaten Tugenden in Nischen und Freiräumen auf der anderen Seite werden von Dahrendorf nicht gegeneinander aufgerechnet. Und das, obwohl die ersten 24 Kapitel seines Buches über eben diese vormodernen Phänomene in der deutschen Gesellschaft nach 1945 handeln ${ }^{51}$. Wenn das Buch also ein zutreffendes Bild der 50er und frühen 60er Jahre zeichnet - was hier nicht zur Debatte steht - drängt sich natürlich die Frage auf, was für eine Revolution das war, die 12 Jahre zugange ist und ihre Wirkungen erst 20 Jahre nach dem Dahinscheiden der führenden Revolutionäre, demnach 32 Jahre nach ihrem Beginn entfaltet, angefangen mit dem Erscheinen des Dahrendorfschen Buches usw. Man könnte etwa vermuten, daß ohne Drittes Reich die Institution Kirche ihre zweite Säkularisierungswelle bereits ab 1950 erlebt hätte, nicht zwanzig Jahre später ${ }^{52}$. Die nationalsozialistische Schulpolitik »reformierte « das Erziehungssystem - unter günstigeren sozialen und demographischen Bedingungen einzig nach dem durch die Reformpolitik der Weimarer Republik vorgegebenen $\mathrm{Mu}$ ster und auf dem bereits angedeuteten Weg, neue Systeme höchst zweifelhafter Qualität und vorrangig politischen Charakters neben die alten zu setzen: die NS-Ausleseschulen und die HJ. Der Output dieses zweiten Systems kam auch nicht, so darf man dem bisherigen Forschungsstand nach jedenfalls vermuten, einer Auffrischung der bestehenden Eliten zugute, sondern der SS, also wieder einer NS-Nebenelite, deren Überleben einigermaßen zweifelhaft war ${ }^{53}$.

Dagegen lautet der Trend moderner Schulpolitik - so war es jedenfalls bis vor kurzem Übergang von einer vertikalen Gliederung (Bildungsgangschule) zu horizontaler (Stufenschule). Die Stationen der Entwicklung des deutschen Schulsystems waren die reform- und experimentierfreudige Weimarer Republik und der Beginn westdeutscher Schulreform mit dem Hamburger Abkommen der Kultusminister von 1964. Das NSRegime hat zwar die Reformmaßnahmen der Weimarer Zeit zu konsolidieren gewußt (Abbau der Privatschulen, Dreigliedrigkeit), kann deshalb aber kaum des Setzens von Meilensteinen gerühmt werden. Nicht nur wegen des kriegsbedingten Scheiterns der Hauptschule: sie war wenig anderes als die schon bestehende und um zwei Klassen verkürzte Mittelschule ${ }^{54}$. Weder die Unterrichtung in völkischer Inbrunst noch die Entwissenschaftlichung der Volksschullehrerausbildung (die keineswegs kriegsbedingt 
war, die Kriegsbedingungen lieferten nur zusätzliche Argumentationshilfe) lassen sich ernsthaft als Modernisierung des Schulwesens verstehen. Eine weitere wichtige "Reform «, die Vereinheitlichung des Schulwesens auf Reichsebene, machte trotz einiger Anstrengungen wenig Fortschritte, kam 1945 nicht nur zum Stillstand, sondern war derart diskreditiert, daß noch 1980 daran niemand anzuknüpfen wagte, und ob bildungspolitischer Zentralismus der Moderne höchstes bildungspolitisches Ziel sein muß, hat auch schon mancher in Zweifel gezogen ${ }^{55}$.

Daß Dahrendorf von einer Beseitigung der autonomen Institutionen der Wirtschaft ausgeht, entspricht nicht ganz den Tatsachen, ist beim damaligen Forschungsstand aber auch nicht verwunderlich. In diesem wie in anderen Bereichen ist das Kennzeichen der nationalsozialistischen Herrschaft ja gerade, daß kein Elitenaustausch stattfand und ohne erhebliche Komplikationen auch nicht stattfinden konnte. Es dürfte zwar wiederum etwas untertrieben sein, von einem Formwandel der Konkurrenz auszugehen, diese aber als "überwiegend marktwirtschaftlich geordnet " zu beschreiben, wie es Volker Hentschel tut. Aber die unabkömmlichen Fachkräfte taten eben in neugeschaffenen oder lediglich umgetauften Institutionen ihren Dienst ${ }^{56}$. Die unzweifelhaft normenauflösende Qualität der nationalsozialistischen Herrschaft ist hier (wiederum) nicht mit der mangelnden normensetzenden Kompetenz der Nationalsozialisten verrechnet worden. Die in Aussicht genommene Einführung des Gewohnheitsrechts, in der Praxis des Faustrechts, bot bis 1945 keine ordnungspolitische Alternati$\mathrm{ve}^{57}$. Schon bevor er diesen Unternehmungen einen eindeutigen Riegel vorschob, hatte Hitler selbst ja denjenigen seiner Anhänger, die noch immer »die Sozialordnung mittels Handfeuerwaffen umzustülpen« gedachten (ein älteres Bonmot von Arnold Gehlen), schon relativ früh gelegentliche Absagen erteilt, um im August 1934 schließlich zu verkünden, die Revolution müsse, wenn schon, in das ruhigere Fahrwasser der Evolution gelotst werden ${ }^{58}$. Revolutionäre Ziele sollten also nicht gleich in der nächsten Woche, sondern später, und wenn zwar nicht ohne Gewalt, so doch wenigstens ruhigen Blutes und Gewissens installiert werden. Diese deutschen Revolutionäre hatten gegenüber den gleichzeitig tätigen russischen den Vorteil, nicht mit brutaler Gewalt eine Agrar- in eine Industriegesellschaft verwandeln zu müssen, denn die Installationen waren schon gelegt. Es galt nicht, Voraussetzungen des gesellschaftlichen Wandels zu schaffen, sondern vielmehr die Gesellschaft zu veranlassen, ihre kollektive Mentalität zu verändern. An eben diesem Punkt endet die Klarheit. Während des Krieges führte das zur bekannten Vertagung von NS-Utopia bis zu dessen Ende, was wiederum die Eintracht stiftende Wirkung hatte, daß jedermann (die Frauen weniger) sich sein privates Utopia vorstellen konnte: germanisch, agrarisch, als Polizeistaat, mit Säulen oder mit Blümchen usw.

Alles in allem muß wohl geschlossen werden, daß streckenweise erhebliche Freiräume und ein hohes $\mathrm{Maß}$ an Autonomie erhalten blieben, sogar neu hergestellt werden konnten. Daß »Gleichschaltung “ die "Volksgenossen«, wie Dahrendorf meint, »einander gleichgemacht« habe, ist ein nettes Wortspiel, entspricht den Tatsachen aber ebensowenig, wie die Vorstellung von »eine[r] monopolistische[n] Clique «, die an die Stelle vieler Teileliten getreten sei ${ }^{59}$. In methodischer Hinsicht ist die oberflächliche Verwendung einer Art totalitären Verursacherprinzips fragwürdig: es führt auf Abwege, am Ende eines Zeitraums vorgefundene Tatsachen - von ihrem zum Teil zweifelhaften Charakter einmal abgesehen - einzig dem Tun der in dieser Zeit herrschenden Partei zuzuschreiben, auch wenn diese sich noch so totalitär gebärdet hätte.

Es gibt gründlichere Studien, die auch prompt zu differenzierteren Aussagen kommen, ohne daß manche Kritiker das sofort bemerkt hätten. War der Apologie-Vorwurf schon Dahrendorf gegenüber lächerlich, reichte in anderen Fällen noch nicht einmal das wohlselektierte Beweismaterial ${ }^{60}$. Die Oxforder Dissertation David Schoenbaums 
bietet eine einleuchtendere Version ${ }^{61}$. Er geht davon aus, daß der Nationalsozialismus ein Versuch gewesen sei, die marxistische Weltsicht umzukehren, derzufolge das Sein das Bewußtsein bestimmt. Tatsächlich stimmt diese These mit der üblichen NS-Sicht der Dinge überein, ohne daß Schoenbaum sich dessen vollständig bewußt wäre ${ }^{62}$. Die soziale Revolution des Nationalsozialismus war in seiner Sicht eine doppelte Revolution, der Zwecke und der Mittel zugleich, wobei die zweite Komponente die Umkehr der ersten war und diese tendenziell aus dem Verfahren ausschloß ${ }^{63}$. Um der Erreichung seiner Ziele willen, die anti- oder jedenfalls nicht-moderner Natur waren, habe der Nationalsozialismus sich moderner und modernster Mittel zu bedienen gehabt, weshalb bei Abbruch des Versuchs so ziemlich das Gegenteil dessen herausgekommen sei, was man hatte erreichen wollen: Städte und Kapitalkonzentration waren größer als zuvor, die Landbevölkerung kleiner, die Frauen standen in der Fabrik statt in der Küche, die Einkommensverteilung war ungleicher als zuvor, der Mittelstand gehörte dabei zu den Verlierern, die ostelbischen Großgrundbesitzer saßen noch immer auf ihren Gütern, in den Behörden Doktores und in den Generalstäben Adlige.

Auch eine andere Konstante der deutschen Geschichte war erhalten geblieben, die Kluft zwischen historischer Wirklichkeit und ihrer Deutung ${ }^{64}$. Und eben auf die nationalsozialistische Forcierung dieses schizophrenen Selbstdeutungsversuchs kommt es Schoenbaum an. Hans Mommsen hat in einem Vorwort zur Neuausgabe des Buchs auf die Schwachstelle der Interpretation gewiesen, indem er nach der Vermittlung zwischen den unterschiedlichen Ebenen fragt, der gesellschaftlichen und der mythisch-voluntaristischen ${ }^{65}$. Schoenbaum nämlich betreibt seine Interpretation weniger in Widerspruch zum ausgebreiteten Material, wie ihm oft vorgehalten worden ist ${ }^{66}$, sondern scheint den nicht zuletzt propagandistisch inszenierten Schein meßbaren Daten vorzuziehen, ohne immer detailliert aufzudröseln, was hartes Faktum, was Einbildung und inwieweit auch nicht ganz faktengesättigte Wahrnehmung ein Teil der Wirklichkeit ist.

So sieht er, daß im Kampf um Gleichberechtigung nicht die Klassenverhältnisse verändert werden sollten, sondern der Status ${ }^{67}$. Das Kapitel über Aufstiegsmöglichkeiten im Dritten Reich endet mit der Feststellung, die Statuszuschreibung hätte doch zu der allgemeinen Vorstellung beigetragen, das Dritte Reich sei eine offene Gesellschaft - in Beziehung auf die soziale Mobilität, nicht in geistesgeschichtlicher auf Plato und Rousseau, versteht sich $^{68}$. Vielleicht ließen sich der symbolische Aufstieg und die eingebildete offene Gesellschaft besser als deutscher Revolutionsersatz auffassen, fand doch tatsächlicher Aufstieg fast ausschließlich in politischen Apparaten statt, bestenfalls im Staatsapparat, und zu guter Letzt: was macht der $»$ Aufsteiger « nach dem Krieg (auf welchen Zeitpunkt die nationalsozialistischen Reformvorhaben fast regelmäßig verschoben wurden) mit seiner dürftigen Ausbildung? Er bleibt Parteigenosse Marke Unqualifiziert. Auch hier wieder das Phänomen des an die politische Form der Gesellschaft gebundenen "Durchbruchs zur Moderne, ein mit den "Neureichen" des Kaiserreichs, der Weimarer Republik und unserer Tage schwer vergleichbares Phänomen. Natürlich könnten zum Vergleich Parteikarrieren, die in höheren Staatsämtern endeten, oder Parteibücher in ihrer Funktion als Eintrittsbillets herangezogen werden, nur wäre dann schwerlich die Zeit zwischen 1933 und 1939 der Ort des Durchbruchs zur Moderne ${ }^{69}$. Die Statusrevolution war keine Angelegenheit von Dauer. Sollte Schoenbaums Vermutung in die Richtung gegangen sein, die Nationalsozialisten wären wenigstens ihrer eigenen Revolutionstheorie gerecht geworden, beruht sie doch auf sehr vereinzelten Aussagen, die zudem von Volksgemeinschafts-Propaganda nicht unbeeindruckt sind. Für den Bereich der Arbeiterschaft hat die Oral-History-Forschung bislang eine entgegengesetzte Wahrnehmung in der Tradition des Klassenkampfes herausgestrichen. 
Schoenbaums Thesen wurde die hohe Ehre zuteil, in weniger abgewogener Form die Runde durch publizistische und sogenannte fachfremde Publikationen zu machen. Furore machte Joachim C. Fests Hitler-Biographie; der Autor hatte sogar ein passendes Zitat aus den Schriften Heinrich Heines gefunden ${ }^{70}$. Bei Fest hat Hitler ohne Wenn und Aber "sowohl Deutschland als auch weite Teile der von seiner Dynamik erreichten Welt ins 20. Jahrhundert befördert«, indem es ihm gelang, „die Ängste und Entwurzelungsaffekte, die den Bruch mit der Vergangenheit im allgemeinen begleiten, zu dämpfen oder in gesellschaftlich nützliche Energie umzuwandeln«. Weil - bei allem, das den Mann sonst noch bewegte -, der "revolutionäre Gedanke« einer Umwandlung von Staat und Gesellschaft in eine konfliktfreie, militant geschlossene "Volksgemeinschaft « (von Fest selbst mit Anführungszeichen versehen) immer vorherrschend blieb, war die Revolution "sein Werk«, und zwar keineswegs absichtswidrig ${ }^{71}$. Die "gesellschaftlich nützliche Energie« mag einer gewissen Flüchtigkeit beim Abfassen dieser Textzeile zugeschrieben werden, paßt aber zur durchgängigen Vernachlässigung gesellschaftlicher Vorgänge zugunsten der Titelfigur ${ }^{72}$. Greift man wahllos andernorts zu, stößt man auf J. P. Sterns Abhandlung, der etwa bewundert, daß zum ersten Mal in der deutschen Geschichte der erworbene Status über dem zugeschriebenen rangierte ${ }^{73}$. Es handelt sich darum, daß schlicht ein neuer (politischer) Status zugeschrieben und erst damit erworben wurde, von seiner zweifelhaften Zukunft und Tiefenwirkung nicht zu reden. Stern ist mit Daten sparsam, nennt aber immerhin doppelt so viele Unteroffiziere, die während des Krieges zu Offizieren aufstiegen, als in sämtlichen deutschen Armeen seit 1800 zusammengenommen, eine sehr unpräzise und schwer nachzurechnende Angabe, ohne Quellenverweis. Präzisere Beobachtungen ergeben, daß traditionell ein Überschreiten der Korpsgrenzen im deutschen Heer als Verstoß gegen Standesschranken betrachtet wurde, institutionell erst seit Mitte der 60er Jahre die militärfachliche Laufbahn neue Aufstiegsmöglichkeiten bot ${ }^{74}$.

Das Thema Militär führt zu einer weiteren Konstante der Revolutionsinterpretation. Schoenbaum vertritt nahezu durchgängig den Standpunkt, der Nationalsozialismus habe keine der Entwicklungen, die Industriegesellschaften normalerweise eigen sind, aufgehalten. Bereits nach dem bislang abgehandelten bestehen auch gewisse Zweifel, ob er beabsichtigt oder unbeabsichtigt derlei Entwicklungen in Gang gesetzt hat. Einige Projekte sind gescheitert, wie zum Beispiel das bereis erwähnte der Hauptschule oder - anders als Schoenbaum an einer Stelle meint - die Gleichstellung von Arbeitern und Angestellten ${ }^{75}$. Besser sollte es heißen: auf halbem Wege steckengeblieben, denn zwar wurde die amtliche Unterscheidung zwischen Arbeitern und Angestellten aufgehoben, was auch der alten Praxis in der Parteistatistik der NSDAP entsprach, nicht aber die unterschiedliche Sozialversicherung, wie von der Deutschen Arbeitsfront gefordert (das ist übrigens noch heute so), und der bessere Kündigungsschutz für Angestellte blieb auch bestehen.

Die immer wieder bewunderte Verbürgerlichung des Offizierkorps, gar die Vermehrung von Stellen in diesem Korps, liegen im Trend der Aufrüstung und der verhältnismäßigen Verstärkung des Offizieranteils bei technisierter Kriegführung. Die Form der neueingeführten Leistungsbeförderung stand der Sache selbst im Weg, da das an sich moderne - übrigens von den Nationalsozialisten in der ihnen eigenen Art schon während der "Kampfzeit« propagierte - Leistungsprinzip untrennbar mit dem nun wirklich archaischen Bild des Kämpfers verknüpft wurde, letzteres offenbar der genuin nationalsozialistische Beitrag zur Sache ${ }^{76}$. Betrachtet man den Anteil der Selbstrekrutierung des Offizierkorps - was wichtiger ist, als die "vons« zu zählen, da die traditionelle Politik der »erwünschten Kreise « auch höhere Beamte und Akademiker bürgerlicher Abstammung umfaßte - liegen die Prozentzahlen von 1913 und 1944 nahezu gleich (28,1\% und 29,0\%), mit einem steilen Anstieg (bis zu 54\%) in den Weimarer Jahren 
dazwischen, als die winzige Reichswehr ihre Leute sehr sorgfältig auswählen konnte. Die Rekrutierung aus den »erwünschten Kreisen« hatte vor dem ersten Weltkrieg einen Anteil zwischen 70 und 80\%, er stieg in der Weimarer Republik auf fast 90\%, fiel im Zuge der Aufrüstung stark ab und zog nach 1945 bis zum Beginn der 60er Jahre wieder an, immerhin auf einen Satz von 38\% im Jahre 1962. Die soziale Umschichtung erreichte ihr größtes Ausmaß erst um die Wende der 70er Jahre ${ }^{77}$. In diesem Zusammenhang scheint die planmäßige Ausrottung des deutschen Adels eine Legende zu $\operatorname{sein}^{78}$, Neuerungen erfolgten den militärischen und militärtechnischen Erfordernissen entsprechend, sie wurden durch nationalsozialistische Zutaten eher verwässert. Hätte, anders gesagt, ein kaiserliches Deutschland 1939 einen Krieg vom Zaun gebrochen und diesen fünfeinhalb Jahre geführt, hätte es ebensovieler bürgerlicher Offiziere bedurft, und ebensoviele adlige wären gefallen. Für das Kaiserreich ist, mit Hilfe leicht angespannter Phantasie, vielleicht auch vorstellbar, daß es sein Offizierkorps unterbesetzt gehalten hätte nach dem Motto: klein, fein, aber leider nur Kavallerie.

Bevor derlei scheinbare Negativbefunde zu dick aufgetragen sind, einige gegenläufige Entwicklungen: Die Frauenpolitik des Regimes läßt sich nicht ausschließlich als Konflikt zwischen vormoderner Ideologie und moderner Notwendigkeit begreifen, vielmehr wurde, wie feministisch beeinflußte Studien betonen, über den pragmatischen Ausweg des »wesensgemäßen Einsatzes« der Frau, das heißt in untergeordneter Stellung bei der stupidesten zur Verfügung stehenden Tätigkeit, der Kernbestand der erst seit wenigen Jahren abbröckelnden Erkenntnisse der Arbeitspsychologie und Lohnpolitik moderner Zeiten kopiert ${ }^{79}$. Man muß kein ausgewiesener Frankfurter Schüler sein, um im Dritten Reich ganz gewöhnliche Schattenseiten der Moderne zu entdekken. Wieder anders, sind - »theoretisch « - auch emanzipatorische Chancen der Frauen zur Diskussion gestellt worden, doch scheint dieser Ansatz noch überarbeitungsfähig ${ }^{80}$. Über den Grundsatz der Leistungsbezogenheit in der NS-Sozialpolitik ließe sich ähnliches sagen. Die Methoden waren durchweg moderner als die Vokabeln. Die Rezepte jedoch stammten auch in diesem Fall größtenteils von der an sich recht fortschrittlichen Arbeitswissenschaft und aus den Erfahrungen mit Rationalisierungsmaßnahmen in der Weimarer Republik ${ }^{81}$.

Wir brauchen uns nicht lange damit aufzuhalten, daß der NS-Staat den Trend zur Konzentration in der Wirtschaft durch fiskalische Maßnahmen kräftig förderte (zugleich aber in der Zeit ab 1942 eine gewisse Verlagerung der ursprünglich preis- und wettbewerbspolitischen Funktionen zugunsten einer kontingentierungspolitischen verzeichnet werden muß) ${ }^{82}$. Da aber von moderner Gesellschaft(spolitik) die Rede ist, sollte nicht ganz unbeachtet bleiben, daß nicht zuletzt im Interesse zunehmender staatlicher Auftragstätigkeit dazugehörende Maßnahmen staatlicher Gegensteuerung in diesem System fehlen. Eigentlich ganz unerheblich, doch liegt immerhin ein Bruch vor zwischen den Ansätzen einer Antikartellgesetzgebung in der Weimarer Republik (Verordnung gegen den Mißbrauch wirtschaftlicher Machtstellung von 1923, Kartell-Notverordnung von 1930) und dem Gesetz gegen Wettbewerbsbeschränkungen von $1957^{83}$.

Eine andere Entwicklung, die vermutlich stärkeren Eindruck in weiten Kreisen der Bevölkerung hinterließ, läßt sich in der Architektur des Dritten Reichs beobachten. Wir haben es weder mit einem Abbruch der Moderne, noch mit lediglich kriegs- und rüstungsbedingten Verzögerungen der Rückkehr zur Vormoderne zu tun. Die offizielle Monumentalarchitektur des Regimes läßt sich als Kombination modernen und neoklassizistischen Baustils einordnen ${ }^{84}$, Hitler selbst suchte in seinen öffentlichen Äußerungen stets sowohl der modernen wie auch der traditionellen Stilrichtung gerecht zu werden. Während die HJ ihre Heime in ländlichem Stil zu gestalten beliebte, baute die Partei Ordensburgen in einer Mischung aus mittelalterlichen und modern-funktionali- 
stischen Elementen, die Luftwaffe hingegen bevorzugte Hypermodernes. Eine offiziöse Publikation sah sich darob veranlaßt, statt wie bisher üblich von Funktionalismus nun eben von "kristallklarem Funktionalismus« zu reden ${ }^{85}$. Während des Krieges mußte auf ästhetische Bemühungen zunehmend verzichtet werden, übrig blieb ein kühler Funktionalismus ganz eindeutig in der Tradition der radikalen Architektur Weimarer Zeiten $^{86}$.

Der staatliche Wohnungsbau läßt keinerlei Anstrengungen erkennen, mit einer Rückführung städtischer Massen auf das Land Ernst zu machen. Die wenigen Kleinsiedlungen, die nach 1933 entstanden, gehen auf ein Programm des Jahres 1931 zurück, bei der Masse der Projekte wurde die Praxis des Appartmentbaus an der Peripherie der Städte fortgesetzt. Auch am Stil der Häuser änderte sich wenig, allenfalls bisweilen durch die Ausrüstung mit vertikalen Fenstern und hölzernen Fensterläden ${ }^{87}$. Am Beispiel Wolfburgs hat Marie-Luise Recker die Baupolitik in einer NS-Musterstadt insgesamt als ambivalent-pragmatisch bezeichnet ${ }^{88}$, was wohl für die Baupolitik allgemein Geltung beanspruchen kann, wenn man die zuvor erwähnten Großprojekte Hitlers einmal ausklammert. In dieser Hinsicht ist also kaum eine Abweichung vom Trend zu beobachten. Während des Krieges erforderte der massenhafte Einsatz ungelernter Arbeitskräfte den Fertigteilbau, welcher widerum der Typisierung und Normierung im Bauwesen zum Durchbruch verhalf. Wie wenig das mit Nationalsozialismus zu tun hat, zeigt die Tatsache, daß mit den Plänen aus Albert Speers "Arbeitsstab zum Wiederaufbau bombenzerstörter Städte« der Wiederaufbau nach 1945 bewerkstelligt wur$\mathrm{de}^{89}$.

Man kann sicher darüber streiten, ob rein funktionaler, technizistischer Stil moderner ist, als eine Verbindung von Technik, Natur und dem, was die meisten Menschen als irgendwie angenehm empfinden, was also meist auf traditionelle Formgebung hinausläuft. In diesem Zusammenhang lohnt es festzuhalten, daß unter Fritz Todt eine Konzeption des Autobahnbaus durchgesetzt wurde, diese als Repräsentationsbauwerke und zugleich als Musterbeispiel dafür zu planen, wie Technik in die Landschaft eingepaßt werden konnte. Zu diesem Zweck bekam 1934 jede Bauleitung - gegen den Widerstand der »Baubullen « betitelten Ingenieure - einen »Landschaftsanwalt« zugeteilt. Die nach dem Konzept Todts in Schwingungen angelegten Trassen wurden nach dem Krieg wieder abgeräumt, denn rein technokratisch denkende Straßenbauer empfanden sie als höchst überflüssige ideologische Zutaten, die begradigt werden konnten ${ }^{90}$. Von derlei Nischen abgesehen, ist es wohl richtig, den Nationalsozialismus als "technokratische Bewegung in romantischem Gewand ${ }^{91}$ zu bezeichnen, jedenfalls unter dem Gesichtspunkt seines Verhältnisses zu Technik und Natur. Je nach persönlichem Zuschnitt des Bauherrn erfreute sich das eine oder das andere Element größerer Wertschätzung, sofern die jeweiligen Prioritäten des Regimes: Arbeitsbeschaffung, Aufrüstung, landwirtschaftliche Erzeugungsschlachten oder militärische Effizienz ausreichende Spielräume ließen. In dieser Hinsicht ist die These Rolf Dieter Sieferles weniger als strategisch-intentionales Handeln zu verstehen als in Form des Eisenstadtschen Modells der ausgeglichenen Koexistenz moderner und vormoderner Strukturen, wie zum Beispiel durch die erwähnten Fensterläden sinnfällig gemacht werden sollte. Andernfalls besteht Gefahr, die Debatte um die NS-Revolution mit Hilfe längst überholter sozialwissenschaftlicher Theorien zu führen (Durchbruch zur Moderne, Dichotomie eines modernen und eines vormodernen Gesellschaftstypus) ${ }^{92}$.

Wiederum weiter im sozialen Bereich liegt der oft hervorgehobene Ausbau der Massenkommunikationsmittel, insbesondere des Rundfunks. Daß hier von Programmvielfalt nur am Rande die Rede war ${ }^{93}$ versteht sich von selbst, dagegen weniger die offenbar hohe Affinität zu Erscheinungen US-amerikanischen Zuschnitts auf dem Gebiet der Massenkultur und des Massenkonsums, sofern von letzterem überhaupt die Rede 
sein kann ${ }^{94}$. Es hat den Anschein, als seien auch auf diesem Gebiet Trends der Weimarer Zeit eher pragmatisch weitergeschrieben als ideologisch bedingt zusammengestrichen worden, was in einem gewissen Gegensatz zum meist ausführlich gewürdigten "Exodus der Kultur “, sprich: der höheren, feuilletonpflichtigen steht ${ }^{95}$.

Einschränkungen müssen nach Ausweis einer neueren Untersuchung auch hinsichtlich des hohen Stellenwerts gemacht werden, welcher der NS-Gemeinschaft Kraft durch Freude beim Durchbruch zum Massentourismus gewöhnlich eingeräumt wird. Nicht nur, daß der Tourismus unter den verschiedenen Tätigkeiten der KdF eine vergleichsweise geringe Rolle spielte ${ }^{96}$, auch im Dritten Reich reiste weniger die Arbeiterschaft als der auch zuvor schon reisefertige Mittelstand. Das Beispiel macht auch die gereizte Reaktion des bisher in seinen Kurorten unter sich weilenden Bürgertums deutlich, vor allem aber den Erfolg seines Widerstands gegen die »Volksgemeinschaft«: 1939 waren die deutschen Bäder und Kurorte wieder KdF-frei, von offizieller Seite wurde nun die Trennung des einfachen vom gehobenen Tourismus propagiert und praktiziert. Neu war die Durchsetzung des bezahlten Jahresurlaubs, der bislang weder für die Gewerkschaften noch für die Arbeitswissenschaft ein Thema war ${ }^{97}$. Auf dieser Grundlage bedurfte es nur noch einer Steigerung des Reallohns, um langsam den heutigen, modernen Stand des Massentourismus zu erreichen.

Die vordergründige Revolutionierung des landwirtschaftlichen Erzeugungssystems durch den Reichsnährstand krankte zunehmend am Konflikt ordnungspolitischer Ziele mit kurzfristig notwendigen Maßnahmen, welcher wiederum traditionsgemäß zugunsten der Großbauern gelöst wurde. Das Herausnehmen der Landwirtschaft aus den Marktzusammenhängen erfuhr zwar eine gewisse Perfektionierung, von einer Umwälzung der Verhältnisse kann jedoch kaum gesprochen werden, die Kosten gingen - wie zuvor und danach - zu Lasten der kleineren Bauern ${ }^{98}$.

Bleibt zuletzt noch »eine gewisse Schwächung und Infragestellung provinzieller sozialkonservativ [. . . ]-patriarchalischer Sozialverhältnisse«, die Elke Fröhlich als ein Ergebnis des großangelegten Projekts "Bayern in der NS-Zeit« vorgestellt hat. Konkret: Zurückdrängen des kirchlichen Einflusses auf die Schulerziehung, Rütteln zumindest an den strengen kirchlich-patriarchalischen Normen der Jugenderziehung durch die HJ und partielles Aufbrechen des Systems sozialer Kontrolle der Landarbeiter durch Bauern, Landräte und Gendarmerie" ${ }^{99}$. Bleibt die Frage offen, ob die Trostlosigkeit der bayerisch-provinziellen Sozialverhältnisse nach dem spurlosen Verschwinden der Partei im Frühjahr 1945 nicht doch zeitweilig restauriert wurde. Eine revolutionäre Veränderung sozialer Zustände und Normen wird in Elke Fröhlichs Beitrag jedenfalls ausdrücklich in Abrede gestellt. Daß in den 50er Jahren der Bundesrepublik Benimm und Anstand wieder zur Weltanschauung wurden, ob in Ermangelung leichter zu handhabender Traditionen oder nicht, scheint eher für die verzögernde Wirkung langsamen Wandels der nationalsozialistischen Herrschaft zu sprechen als für deren beschleunigenden oder gar revolutionierenden Effekt ${ }^{100}$.

III.

Eine Eigentümlichkeit der Diskussion um Faschismus beziehungsweise Nationalsozialismus und Modernisierung ist, daß auf einen Beitrag zum deutschen Fall bisweilen mit dem italienischen Beispiel gegenargumentiert wird, oder andersherum. Das Ergebnis derartiger Debatten, sofern eines auszumachen ist, lautet regelmäßig: zwei entgegengesetzt am Rad der Geschichte zu drehen suchende Bewegungen in unterschiedlich entwickelten sozioökonomischen Systemen.

Franz Borkenau darf auch in der Diskussion um den italienischen Faschismus als Klassiker gelten, denn er bescheinigte bereits 1932 dessen Qualität als „Übergangszustand 
[...] zur Schaffung des industriellen Kapitalismus«, als sogenannte Entwicklungsdiktatur, die auch im Zentrum der noch anhaltenden Debatte steht ${ }^{101}$-, in die italienische Historiker übrigens so gut wie nicht eingegriffen haben. Borkenau ging von einer kongruenten Entwicklung »des Kapitalismus« und demokratischer Formen aus - eine bis heute fast ungetrübte Grundannahme der Modernisierungstheorie ${ }^{102}$ - und erblickte die Funktion des Faschismus darin, der jeweils zurückgebliebenen Komponente zur Entwicklung verhelfen zu wollen ${ }^{103}$.

Ein Blick auf die bis heute andauernde Debatte um Italiens industrielle Entwicklung ist in unserem Zusammenhang von Interesse, weil sie deutlich macht, wie ursprünglich einander widersprechende Positionen durch die Entwicklung der Forschung aufgelöst werden, und am Ende alles andere als eindeutige Aussagen über modernisierende Tendenzen oder antimodernistische naheliegen. Die italienische Wirtschaftsgeschichtsschreibung der Nachkriegszeit identifizierte die Wirtschaft der Demokratie mit Freihandel, privater Initiative und Konkurrenz. Eine so strukturierte Wirtschaft entspräche, so nahm man an, wirtschaftlichem Fortschritt: Innovation und Wachstum, während die faschistische Wirtschaft durch Stagnation, sprich: Monopole, weltwirtschaftliche Isolation und Staatsinterventionismus gekennzeichnet sei ${ }^{104}$. Auf die verzweigten Wege der Forschung näher einzugehen, ist hier nicht möglich, jedoch sei auf eine Wendemarke und eine neuere vorzügliche Gesamtbilanz hingewiesen. Ester Fano Damascelli wies in einem 1971 erschienenen Aufsatz ${ }^{105}$ die liberale (und von den Marxisten übernommene) Stagnationsthese als den tatsächlichen italienischen Verhältnissen unangemessen zurück. Als Land an der Peripherie der kapitalistischen Zentren und abhängig von den Strukturen der internationalen Arbeitsteilung waren Staatsinterventionen, Monopole, Einschränkung des Konsums usw. in seiner Sicht angemessene Merkmale des italienischen Entwicklungsmodells, nicht aber irgendwelche Abweichungen ${ }^{106}$. Die ökonomische Struktur des Landes in der faschistischen Zeit entsprach demzufolge der historischen Entwicklung, die Wachstumsraten wichen nicht merklich vom Trend ab, vor allem aber wurde der Grundstein des wirtschaftlichen Wachstums der 50 er Jahre gelegt.

Im einzelnen heißt das: der Faschismus schob eine Lösung struktureller Probleme der italienischen Wirtschaft auf, etwa im Bereich der rückständigen Landwirtschaft des Südens, der permanenten Arbeitslosigkeit, niedrigen Kapitalrendite, Überkonzentration auch des Kleingewerbes, der extremen Abhängigkeit von fremden Märkten usf., beschränkte sich statt dessen darauf, die Löhne zu kontrollieren und während der Weltwirtschaftskrise das Bankwesen zu sanieren, indem es staatlicher Kontrolle unterstellt wurde.

Eine genaue Darstellung dieses durchweg pragmatischen und kaum genuin faschistisch zu nennenden Vorgangs ist der 1980 erschienenen Wirtschaftsgeschichte des Faschismus von Gianni Toniolo zu verdanken ${ }^{107}$ : Die privaten Investmentbanken hatten in den 20er Jahren kurzfristige Kredite der Zentralbank als langfristige Kredite an die Industrie weitergegeben und verloren nun während der Depression ihre Liquidität. Der Staat war zur Intervention gezwungen, andernfalls hätte die Krise ebenso katastrophale Ausmaße angenommen wie in Deutschland. Daß die privaten Banken für garantierte staatliche Kredite industrielle Sicherheiten überlassen mußten schuf die Grundvoraussetzung einer Reorganisation der Industriestruktur und war zugleich der wesentliche Faktor der Rüstungskonjunktur nach 1935. Diese Maßnahmen lassen sich kaum als spezifisch faschistische identifizieren. Anders gesagt: eine liberal-interventionistische Regierung wie diejenigen von Giovanni Giolitti oder Sideny Sonnino hätte nicht anders gehandelt ${ }^{108}$. Weisen also weder Statistiken noch politische Aktionen auf eine faschistische Revolutionierung des italienischen Wirtschaftssystems als vielmehr auf einen überaus normalen Geschäftsgang, so spricht alles für die Richtigkeit der von Char- 
les S. Maier geäußerten Vermutung, der Faschismus sei am besten in seiner Politik zu verstehen, nicht anhand seiner Ökonomie. Diese hätte ebenso, wie das westliche Management generell, auf die scharfen Herausforderungen von Wirtschaftskrise und Krieg zu reagieren versucht ${ }^{109}$.

Wie schon am deutschen Beispiel vorexerziert wurde, versucht auch die modernisierungstheoretisch beeinflußte Analyse des italienischen Faschismus, neue Aufschlüsse über Entstehungs- und Erfolgsbedingungen der Bewegung und über den Output des Regimes, gemessen an den Zielen der frühen faschistischen Bewegung, zu erlangen. Es fällt auf, daß die im folgenden vorgestellten Analysen auf diese Ziele vergleichsweise sorgfältiger eingehen, als die entsprechende Nationalsozialismus-Forschung es tut. Offenbar sind die faschistischen Ziele in unserem Zusammenhang ergiebiger.

A. F. K. Organski und Gino Germani entwickelten höchst abstrakte Modelle in der Absicht, Konstellation und Zeitpunkt einer faschistischen Machtübernahme zu bestimmen ${ }^{110}$. Bei Germani stellen die sogenannte primäre Mobilisierung der unteren Bevölkerungsschichten und die sekundäre der mittleren das zentrale Problem dar; was den Zeitpunkt anbelangt, stellt sich das Problem nach Organski in einer zweiten Phase des Modernisierungsprozesses, in welcher die Aufgaben des politischen Systems (vermutlich) vorrangig in der Distributionssphäre liegen ${ }^{111}$. Tritt zu diesem Zeitpunkt eine Lage ein, die bei Eliten und Mittelschichten zu nachhaltiger Verunsicherung führt (was in etwa Germanis sekundärer Mobilisierung entspricht), gewinnt ein faschistisches Regime an Wahrscheinlichkeit, und zwar als »Versuch sozialer Demobilisierung “ der Unterschichten ${ }^{112}$. Da es auf diesem Abstraktionsniveau schwierig ist, eindeutige Aussagen zu formulieren, räumt Organski vorsichtig »irgendeine Verbindung « zwischen Faschismus und Mobilisierung ein, und kommt, was das Regime anbelangt, zu dem Schluß, in ihm sei es lediglich zu einer Zunahme der politischen Mobilisierung gekommen $^{113}$.

Sofern diese Analyse nicht um weitere Variablen vermehrt wird, eröffnet sie dem demokratischen Verfassungsstaat wenig rosige Aussichten. Ist doch sein System organisierter Interessenvertretung nicht zu Unrecht als "primär ein System der erbitterten Verteidigung des Status quo bei fortschreitender Verengung der Spielräume politischen Handelns bezeichnet worden ${ }^{114}$. Denkt man an Partizipations-, Legitimitäts-, Distributions- und selbst Integrationskrisen unzweifelhaft moderner Industriegesellschaften, wird deren Charakterisierung als "Modernisierungskrisen« zweifelhaft, es sei denn, der Prozeß der Modernisierung wäre ein grundsätzlich nicht abschließbarer, wofür vieles spricht. Dann wiederum wären wir mit dem Problem konfrontiert, ob es sich bei einigen der analysierten vormodernen Faktoren nicht auch um anthropologische Konstanten oder ähnliches handeln kann usw.

Historiker interessieren sich eher für die Absichten handelnder Personen oder Kollektive, als für generelle Gesetzmäßigkeiten. Alan Cassels kommt so zu einer Gegenüberstellung des einer entwickelten Gesellschaft entwachsenen und seiner Meinung so radikalen wie rückwärtsgewandten Nationalsozialismus mit dem Faschismus, der sich einer relativ unterentwickelten Gesellschaft auf recht konventionelle Art, dazu noch mit etablierten Mächten im Bunde, als Agent der Modernisierung vermittels Korporativismus präsentiert habe ${ }^{115}$. Dieselbe Sache, der Korporativismus, dient demnach der einen Bewegung als progressive Sozialphilosophie, der anderen, einer Imitation wie manche meinen, gerät das Konzept zur Reminiszenz an die verlorene Welt der mittelalterlichen Gilden ${ }^{116}$. Da die Sicht des italienischen Korporativismus als Strategie gesamtgesellschaftlicher Rationalisierung von einer neueren Studie bestätigt wird ${ }^{117}$, bleibt nur, den deutschen Fall noch einmal genauer zu betrachten, eventuell unter Verwendung der Argumente von Theoretikern des Neokorporatismus, Schmitter, Heinze oder Offe ${ }^{118}$. 
Die Erhellung des Phänomens verfolgt ebenfalls, nur aufwendiger, Edward R. Tannenbaum in einem Aufsatz über die Ziele des italienischen Faschismus ${ }^{119}$ : nicht Konterrevolution, sondern eine andere Revolution sei das gemeinsame Ziel der faschistischen Fraktionen gewesen, erreicht worden seien nur die politische Mobilisierung der Mittelschichten und nationale Illusionen ${ }^{120}$. Tannenbaum vermutet, diese Akzentverschiebung habe sich aus dem dominierenden Einfluß der nationalistischen Fraktion ergeben, deren Ziele ein autoritärer Staat, die Vermeidung von Klassenkampf durch Zusammenführen der Produzenten in Korporationen und die Ausschaltung als nutzlos angesehener Konkurrenz durch eine Art Neomerkantilismus waren ${ }^{121}$.

Ist hiermit das Problem des faschistischen Pluralismus angerissen, stellen die Beiträge von Roland Sarti und Charles S. Maier die Debatte stärker in den Rahmen allgemeiner Entwicklungstendenzen und -bestrebungen kapitalistischer Gesellschaften ${ }^{122}$. Sartis Betrachtung stellt den Produktivismus in den Mittelpunkt, welchen er vor allem in seiner Funktion als äußerst flexible politische Ideologie würdigt. Gemessen an den verkündeten Zielen könne von einer Revolution in der Tat nicht gesprochen werden, ungeachtet dessen hätte die faschistische Zeit aber signifikante Veränderungen gebracht ${ }^{123}$. Was an dieser Modernisierung, sofern davon die Rede sein kann, spezifisch faschistisch gewesen sein soll, bleibt unklar. Maier spezifiziert die faschistische "Vision industrieller Produktivität « als das Versprechen einer Nicht-Nullsummen-Welt, in der Klassen nicht weiter auf Kosten anderer Klassen prosperieren sollten ${ }^{124}$, eine besonders für Italien wahrhaft glückvolle Verheißung, die andernorts auch schon schlicht als Steigerung des Bruttosozialprodukts definiert wurde, im vorliegenden Fall allerdings nicht wahr wurde ${ }^{125}$.

A. James Gregor, der in einer ganzen Reihe von Veröffentlichungen den modernen Charakter der faschistischen Ideologie und die ökonomischen Modernisierungsleistungen des Regimes betont hat ${ }^{126}$, kommt in einem neueren Buch, neben den alten, in der Zwischenzeit nahezu einhellig abgelehnten Thesen ${ }^{127}$ auch auf die Domestizierung der italienischen Arbeiterschaft zu sprechen ${ }^{128}$. In der Tat die einzige unbestrittene und bis dato genuin faschistische Entwicklungshife, die sich aber auch auf den politischen Raum beschränkt. Auf derselben Ebene ist auch Philip V. Cannistraros Lösung der Frage nach einer faschistischen Revolution angesiedelt ${ }^{129}$ : Er stellt die These von einer Konzentration des Regimes auf die Kulturpolitik seit 1925 auf, schreibt ihm die Einführung einer neuartigen Massenkultur in Italien zu, wobei er besonders die zentrale Bedeutung der Politik mit und gegenüber den Massenmedien hervorhebt ${ }^{130}$. Wie Tannenbaum sieht er dabei in erster Linie die nationalistische Fraktion am Werke, deren Vorstellungswelt dann die Themen entsprachen: Italien als wohlgeordnete, mächtige Nation. So sieht auch Renzo De Felice hier einen Zusammenhang des von ihm hervorgehobenen Problems der Konsensbildung mit der Verbreitung von Zukunftsperspektive: "In diesem Sinn war der Faschismus als Bewegung ein Versuch, neue smoderne und rangemessenere Lösungen zu finden«, äußerte er in seinem bekannten Interview, von daher erklärten sich auch "bestimmte moderne, nicht traditionelle Formen des Korporativismus und bestimmte nicht klassenspezifische Lösungen " ${ }^{131}$.

Insgesamt liegt so der Eindruck nahe, daß »das Beeindruckende der Leistungen des faschistischen Regimes auf wirtschaftlichem und sozialem Gebiet das [ist], was unterlassen wurde«, wie Gordon A. Craig formulierte ${ }^{132}$. Er ergibt sich, soll abschließend ergänzt werden, weil in einigen der vorgestellten Beiträge deutlicher als am deutschen Fall herausgearbeitet wurde, welche Entwicklungen in der Zeit des Regimes originelle faschistische Maßnahmen sind, welche dagegen in Traditionen und Struktur des Landes angelegt, somit von fast jeder anderen Regierung auch durchgeführt worden wären, oder was einfach sich selbst tragender Trend beziehungsweise »normale« Reaktion auf weltwirtschaftliche Veränderungen war. 
Gegenwart ist erklärungsbedürftig. Wer Probleme der Gegenwart nicht für Mißmanagement halten will, ist auf die Vergangenheit verwiesen, auf eine historische Erklärung ${ }^{133}$. Erklärung der Gegenwart war so, seit den Anfängen des Fachs, neben einem eher verstohlenen Blick in die Zukunft, die stets vornehmste Aufgabe der Historiographie. Nicht in jedem Fall konnte dabei der Eindruck vermieden werden, die gegenwärtige würde als die beste aller möglichen Welten empfunden. Was unsere eigene anbelangt, ist darin auch sicher keine abwegige Idee zu entdecken. Fraglich ist nur, ob ein Muß der politischen Bildung auch uneingeschränkt als Kontrastfolie der historischen Wirklichkeit brauchbar ist. Ein weiteres Element kaum minderer Fragwürdigkeit kommt hinzu: vergegenwärtigen wir uns, daß Modernisierungstheorien in erster Linie als wissenschaftliche Hilfsmittel der Entwicklungspolitik gedacht waren ${ }^{134}$, wird ein gewisser teleologischer Grundzug erkennbar. Wollte man auf der Basis den Versuch wagen, diese Theorien auch als Produkte des Fortschrittsdenkens der jüngeren europäischen Geistesgeschichte und damit als eine der letzten Varianten säkularisierter Heilsgeschichte zu enttarnen ${ }^{135}$, stieße man vermutlich eher auf konstante Denkfiguren, als auf "Paradigmawechsel«.

\author{
Das sei dir Lobgesang! \\ Du, der du lenkst \\ Mit weiser, weiser Allmachtshand \\ Das bunte Zeitengewimmel,
}

dichtete Hölderlin, nicht zuletzt in trostspendender Absicht, schrieb er doch gegen Ende der revolutionären Schreckensherrschaft in Frankreich auch: "Das erstemal, daß das Gesetz der Freiheit sich an uns äußert, erscheint es strafend. « ${ }^{136}$ Auch Heinrich v. Treitschke war derlei metaphysische Heilsgewißheit geläufig. „Über dem bunten Wirrsal waltet", gab er geneigten Lesern des dritten Bandes seiner Deutschen Geschichte 1886 kund und zu wissen, "die Notwendigkeit einer erhabenen Vernunft « ${ }^{137}$. Dabei waltete die im vorliegenden Fall nur über Preußens Erstarken gegenüber der österreichischen Vormacht zwischen 1819 und 1830, eine recht profane Angelegenheit also. Die Geschichtsphilosophie der Französischen Revolution neigt dazu, der Geschichte einen Sinn zu geben, den sie in der Realität nicht aufweist, obwohl er als Hypothese durchaus brauchbar ist. Das liberale Telos hat schmerzliche Feststellungen, wie die zitierte Hölderlins, glücklicherweise überlebt, denn als politisches Handwerkszeug ist es ganz unentbehrlich, als Sinndeutung der Geschichte aber sehr wohl ${ }^{138}$. Ist Geschichte nicht eine Abfolge permanenter Anpassungsleistungen, haben wir es in Fällen von Katastrophen nicht mit unzureichenden Anstrengungen oder unterlassenen zu tun? Mit Versuchen jedenfalls, Geschichte zu bewältigen, weit eher, als damit, sie bewußt zu gestalten?

Natürlich nicht so platt, wie hier wiedergegeben, liegt doch das "Erkenntnisinteresse « der modernisierungstheoretisch beeinflußten Geschichtsschreibung nicht weniger offen als seinerzeit Heinrich v. Treitschkes: mit den spätestens 1945 abgeräumten feudalistischen und absolutistischen Relikten wurde die deutsche Gesellschaft zugleich von den Ursachen ihrer Katastrophe befreit ${ }^{139}$.

Das Dilemma der modernisierungstheoretischen Geschichtsphilosophie, wenn sie in Verbindung mit dem Revolutionsbegriff auftritt, ist die Frage nach den Grenzwerten: ist die Moderne das Ergebnis des Modernisierungsprozesses oder ist es die sogenannte Post-Moderne, wie läßt sich das Ergebnis eindeutig vom Entstehungsprozeß abgrenzen? Zumal, wenn der Grenzpfosten »Revolution« heißen soll? 
Der Krieg ist aus der Geschichte des Nationalsozialismus nicht fortzudenken, er gehört als integraler Bestandteil zu einer Gesamtansicht des Phänomens, sei es aus systemimmanenten oder persönlichkeitsbedingten Gründen ${ }^{140}$. Überlegungen, als wie großer Mann Hitler in die Geschichte hätte eingehen können, wenn er bereits 1938 verstorben wäre, sind höchstenfalls interessante Gedankenspiele, ansonsten überflüssig. Isoliert man den Krieg jedoch aus analytischen Gründen - ohne zu vergessen, ihn in das Gesamtbild wieder einzufügen - weist der Nationalsozialismus als Bewegung einige Anzeichen einer sozialrevolutionären Bewegung auf, wie auch die gesellschaftliche Situation zur Zeit der »Machtergreifung « nicht zu Unrecht als revolutionär eingeschätzt worden ist, wenngleich zugunsten einer anderen Partei. Dennoch blieb seine Veränderungsdynamik im sozialpolitischen Bereich auf abgeblasene Projekte beschränkt, was auch den potentiell gesellschaftsverändernden Charakter der im Zusammenhang vielbeachteten Jugendpolitik des Regimes fragwürdig erscheinen läßt. Zu guter Letzt machte sich auch unter Nationalsozialisten eine Ahnung davon breit, daß die eigene Revolution Mängel aufwies ${ }^{141}$.

Offenbar ist doch der Bedarf nach Beweismaterial größer, als das Quellenmaterial zur Stützung der vorgeführten Thesen. Es sind eben zwei verschiedene Dinge, historische Abläufe zu systematisieren, oder sie einer vorgefaßten Gesetzmäßigkeit anzugleichen. Die modernisierungstheoretische Sichtweise hat zweifellos etwas Bestechendes; angesichts mangelnder empirischer Befunde muß allerdings die Frage gestellt werden, ob sie nicht am ehesten in sozial- und geschichtsphilosophischer Hinsicht besticht. Und handelt es sich dann nicht um eine Art reflexiver säkularisierter Heilgeschichte? Die Weltsicht des Candide ist schon von Voltaire hinreichend lächerlich gemacht worden, aber vielleicht ist die Bemerkung eines Klassikers der Philosophiegeschichtsschreibung doch von Interesse: bei Descartes' Schülern sei, schreibt Windelband, „der Systemtrieb größer als bei dem Meister “ gewesen ${ }^{142}$. Zur Vollendung brachte bekanntlich Leibniz das System, was aber in unserem Zusammenhang auffällt, ist die Ähnlickeit der explizit modernisierungstheoretischen Position mit etwas wie prästabilierter Harmonie und der Industrie als Zentralmonade.

Eine Erklärung der bemerkenswerten Gradlinigkeit läßt sich einfacher womöglich in einem eher semantischen Vorgang finden: Jürgen Kocka verhalf 1970 dem äußerst nützlichen Begriff »vorindustriell« zum Durchbruch ${ }^{143}$. Das ebenso nützliche Pendant "vormodern « kam leider irgendwo auf den Wegen der Forschung abhanden, und die Verwendung des Terminus "vorindustriell« allein ging hinfort von der Annahme aus, zur Industriegesellschaft gehöre politische Demokratie, was nicht zutrifft, ebenso soziokulturelle, in Form von Gleichberechtigung etwa, bis in den Bereich der Familie hinein. Welche »vormodernen« Verhältnisse in industriellen Gesellschaften ihren Platz haben können, ohne notwendig unerträgliche Kosten oder unerwünschte Reibungen zu verursachen, blieb weitgehend außerhalb des Blickfeldes, eine Frage etwa, was die Moderne eigenlich erst erträglich macht, kam zugunsten des Haftbarmachens "vorindustrieller Faktoren« kaum auf. Wenn "vormodern" und "vorindustriell« gleichgesetzt werden, ergeben sich zu einfache Antworten, graue Katzen werden schwarz (vor allem) und weiß. Das soll nicht heißen, der Historiker stehe vor einer beliebig großen Menge ähnlich sinnloser Fakten, die er bestenfalls aufzählen könne, es ergibt sich vielmehr daraus das Erfordernis, eine äußerst sorgfältige Auswahl von Fakten größerer und geringerer Bedeutung zu treffen, die, in Beziehung zueinander gesetzt, Entwicklungslinien ergeben können, welche wiederum in durchaus mehrdeutigem Verhältnis zueinander stehen mögen. Das sollte nicht als Verweis mißverstanden werden, Geschichte könne nicht in ein System gepreßt werden, aber auch aus sozialwissenschaftlich aufgeschlossener Richtung ist schon argumentiert worden, der Wunsch, dem regellosen Verlauf der Geschichte nicht nur Konturen, sondern einen Sinn zu geben, 
führe, wie andere normative Strategien auch, zu einseitiger Auswahl aus vorgeblichem Reichtum, zu fehlerhafter Identifikation dessen, was "wichtig « ist auch, und gebe dann Strukturen her, die den Sinn nicht her-, sondern entstellen. Das mag auch wieder als Historismus ältester Bauart abqualifiziert werden, wie in der neueren Historismuskritik nicht selten geschehen, nur unterliegt diese Kritik der Gefahr, den Historismus als Methode mit dem Historismus als Ideologie zu verwechseln: historische Besonderheiten gibt es ebenso wie nationale Absonderlichkeiten, und ihre Darstellung überhöht sie keineswegs.

Somit nichts gegen die Verwendung theoretischen Wissens in der Geschichtswissenschaft. Wenn Georg G. Iggers am Historismus kritisierte, er isoliere sich von den Wissenschaften, die nicht das Besondere für sich, sondern allgemeingültige Beziehungen interessieren ${ }^{144}$, dann gilt für einige der hier besprochenen Versuche, daß sie allgemeine Gesetzmäßigkeiten ohne ausreichenden Vergleich auf etwas Besonderes anwenden. Obwohl das geschichtswissenschaftliche Instrumentarium wie das keiner anderen Wissenschaft dazu geeignet wäre, kann kaum die Rede von einer rückkoppelnden Überprüfung sozialwissenschaftlicher Theorien sein, wie sie auch Hans-Ulrich Wehler des öfteren gefordert hat ${ }^{145}$. Auch Wehlers Hinweis, verläßliche Auskünfte seien nur dem "scharfe[n] Säurebad des Vergleichs« zu entnehmen ${ }^{146}$, hat bislang die extrem kurze Liste qualitativ gleichgewichtiger vergleichender Studien nicht merklich verlängert. Eugen Webers Begriff der »alternativen « oder "rivalisierenden« Revolution ${ }^{147}$, erscheint nach alldem, obgleich er empirisch eher durch Untersuchungen der west-, südund südosteuropäischen faschistischen Bewegungen gewonnen wurde, beim gegenwärtigen Stand der Forschung als der mit Abstand brauchbarste. Er trägt 1. dem Selbstverständnis der Nationalsozialisten, oder wenigstens dem des dynamischen Teils der Bewegung Rechnung, verengt also schon die Bewertung der Zielsetzungen nicht auf die Frage nach Übereinstimmung mit anderen revolutionären Bewegungen, bei welcher regelmäßig die Eigentumsfrage dominiert. So bleibt 2. Raum zur Bewertung von Handlungsabläufen wie Ergebnissen der nationalsozialistischen "anderen« Revolution, gemessen am Selbstverständnis der Akteure und zugleich verglichen mit ausdrücklich als andersartig anerkannten Vorläufern und Konkurrenzunternehmungen. Erst auf dieser Stufe ließen sich sinnvoll Übereinstimmungen, Abweichungen und Gegensätzlichkeiten aufzeigen. Rekapitulieren wir die oben zitierte Definition Huntingtons, kann es selbstverständlich nicht nur und nicht zentral um die Einstellung zur Vergesellschaftung oder Verstaatlichung von Produktionsmitteln oder um den Regierungswechsel mit außerkonstitutionellen Mitteln gehen, sei er auch ungleich ruinöser ausgegangen als andere. Ebensowenig braucht vorschnell nach Etiketten wie "rassistische Revolution“ gegriffen zu werden, denn trotz frappierender Durchsetzungsfähigkeit rassistischer Prinzipien bei der Behandlung von Ausländern und Juden gab es auch hier gegenläufige Tendenzen und ist der ganze Komplex der Rassentheorien und -politik viel zu verworren, um eindeutige Ergebnisse überhaupt erwarten zu können ${ }^{148}$. Soll dabei auf sozialwissenschaftliche Hilfestellung nicht verzichtet werden, könnte auch einmal ein Versuch mit der soziologischen Handlungstheorie (Parsons, Smelser, neuerdings Richard Münch) gewagt werden, nur sollte dann auch die Theorie einer empirischen Überprüfung unterzogen werden. Der lediglich heuristische Gebrauchswert sozialwissenschaftlicher Theorien ist oft genug betont worden, der tatsächliche Gebrauch war hingegen oft genug rein affirmativer Art, sei es auch nur im Einleitungskapitel.

Nur in vergleichender Sicht werden sich Wirkungswege spezifisch natinalsozialistischer Politik von industriegesellschaftlichen Entwicklungstendenzen unterscheiden und nationalsozialistische Adaptionen identifizieren lassen, wird man in die Lage kommen, kriegsbedingte Reaktionen von totalitärer Politik sinnvoll zu trennen, obgleich 
beides zur selben Zeit am selben Ort sich abspielte. Im Vergleich mit dem italienischen Faschismus etwa scheint sich anzudeuten, daß die Unterschiede nicht so kraß zu formulieren sind, wie gewohnt (Modernisierungsagenten hie, Antimodernisten da), macht doch die ideologische Orientierung an einer antiken Hochkultur einerseits und auf der anderen an einer archaischen Agrargesellschaft keinen strukturellen Unterschied mehr aus, berücksichtigt man den beiderseits recht pragmatischen Umgang mit modernen Formen, das Beharrungsvermögen bürokratischer Apparate, und läßt man den nationalsozialistischen Antisemitismus einmal beiseite ${ }^{149}$.

Die ideologische Orientierung beider Bewegungen scheint hingegen eher auf die ältere, renovatorische Bedeutung des Revolutionsbegriffs zu deuten ${ }^{150}$, was noch einmal die Brauchbarkeit des von Eugen Weber eingeführten Deutungsmusters unterstreicht. Hat der Nationalsozialismus, wie Leonard Krieger vor einigen Jahren in einem nachdenklichen Artikel meinte, seinen Teil dazu beigetragen, wenigstens unser Verständnis des Phänomens Revolution zu verändern, spricht nichts dagegen, unsere Aufmerksamkeit über ihn hinaus auf andere, dauerhaftere und allgemeinere Tendenzen lenken zu lassen, die im historischen Prozeß mit ihm in Verbindung stehen oder die er zum Ausdruck gebracht hat ${ }^{151}$. Der Zeit des Nationalsozialismus in Deutschland modernisierende Tendenzen absprechen zu wollen, hieße die Augen verschließen vor einer Normalität - oder Banalität - hieße eine Gelegenheit verpassen, in seltener Eindringlichkeit jede Menge Fortschritt auch an der Schattenseite der Moderne aufzuspüren, Abstand von der Vorstellung zu gewinnen, Fortschritt und Zunahme der Freiheit befänden sich im Gleichklang ${ }^{152}$. Wenn der Nationalsozialismus denn eine andere Art von Revolution sein wollte, bleibt der Eindruck einer in vielen Bereichen äußerst dürftigen Art; hinzuzufügen wäre: eine höchst überflüssige war sie auch - aber das unterscheidet sie eben nicht von anderen ${ }^{153}$.

1 Die vorliegende Abhandlung knüpft nicht an die überaus positive Einschätzung der Möglichkeit einer gesamtgesellschaftlichen Perspektive mit Hilfe der Modernisierungstheorie zur Analyse des Nationalsozialismus an, die H. Matzerath/H. Volkmann: Modernisierungstheorie und Nationalsozialismus. In: Theorien in der Praxis des Historikers. Forschungsbeispiele und ihre Diskussion. Hrsg. von J. Kocka. Göttingen 1977 (= Geschichte und Gesellschaft. Sonderheft 3.), S. 86-102, 113-116, bes. S. 88 f. u. 92 ff., vertreten haben. Ich fühle mich den kritischen Kommentaren von W. J. Mommsen (ebd., S. 106 f.) und H.-J. Puhle (ebd., S. 103-106) verpflichtet. H.-U. Thamer: Verführung und Gewalt. Deutschland 1933-1945. Berlin 1986 (= Die Deutschen und ihre Nation. Neuere Deutsche Geschichte in sechs Bänden. Bd 5.), verwendet den Revolutionsbegriff sinnvollerweise in einer sehr zurückhaltenden Weise (vgl. Anm. 20). Daß die angekündigten Bände von W. Schieder (Neue Deutsche Geschichte, C. H. Beck) und H. Mommsen (Propyläen Geschichte Deutschlands) eine entsprechende theoretische Akzentuierung aufweisen werden, ist nach den bisherigen Äußerungen der Autoren zweifelhaft. Mit Spannung darf daher der 4. Band von H.-U. Wehlers Deutscher Gesellschaftsgeschichte erwartet werden.

2 Jüngst M.-L. Recker: Nationalsozialistische Sozialpolitik im Zweiten Weltkrieg. München 1985 (= Studien zur Zeitgeschichte. Bd 29.), ohne Stellungnahme, vgl. auch den Hinweis von M. Broszat: Plädoyer für eine Historisierung des Nationalsozialismus. In: Merkur 435, 39 (1985), S. 383 f., oder M. Prinz: Vom neuen Mittelstand zum Volksgenossen. Die Entwicklung des sozialen Status der Angestellten von der Weimarer Republik bis zum Ende der NS-Zeit. München 1986 (= Studien zur Zeitgeschichte. Bd 30.), mit einer gründlichen Reflektion der »Grenzen der Tiefenwirkung nationalsozialistischer Gesellschaftspolitik“(S. 328-336).

3 Oft in folgender Form: Im Text die Bemerkung, eine Revolution habe stattgefunden und eine Fußnote des Inhalts: Siehe Schoenbaum [wie Anm. 61, unten], entweder die Seite mit der These (S. 26) oder da capo al fine.

4 W. Alff: Thesen zum Kontinuitätsproblem der deutschen Geschichte (1972). In: Ders.: Materialien zum Kontinuitätsproblem der deutschen Geschichte. Frankfurt/M. 1976 (= ed. suhrkamp 714.), S. 14. Als Beitrag zur Erklärung der Hyperstabilität der Bundesrepublik Deutschland unter Berücksichtigung der unmittelbaren Vorgeschichte Ch. E. Frye: The Third Reich and the Second Republic: National Socialism's Impact Upon German Democracy. In: The Western Political Quarterly XXI, 1968, S. 668-680, der einen einheitlichen Wandel sozialer Muster konstatiert (S. 679). 
5 Eindeutig ablehnend m. W. nur K. D. Bracher: Tradition und Revolution im Nationalsozialismus. In: Ders.: Zeitgeschichtliche Kontroversen. Um Faschismus. Totalitarismus. Demokratie. München 1976 und H. A. Winkler: Vom Mythos der Volksgemeinschaft. In: Archiv für Sozialgeschichte XVII, 1977, S. 139.

6 Vgl. J. Kocka: Ursachen des Nationalsozialismus. In: Aus Politik und Zeitgeschichte B 25, 1980, S. 3-25 und T. Nipperdey: 1933 und Kontinuität der deutschen Geschichte. In: Historische Zeitschrift (HZ) 227 (1978), S. 86-111, wieder abgedruckt in: Die Weimarer Republik. Belagerte Civitas. Hrsg. von M. Stürmer. Meisenheim/Königstein/Ts. 1980 (= Neue Wissenschaftliche Bibliothek. Bd 112.), S. 374-392. Paradigma meint die Neuformulierung einer wissenschaftlichen Sichtweise durch Anstoß von außen, also nicht in erster Linie veranlaßt durch wissenschaftsinterne Prozesse, die Falsifikation eines Theorems etwa. H.-U. Wehler hat das mehrfach sehr schön formuliert, z. B.: Bismarcks Imperialismus und späte Rußlandpolitik unter dem Primat der Innenpolitik. In: Das kaiserliche Deutschland. Politik und Gesellschaft 1870-1918. Hrsg. von M. Stürmer. Düsseldorf 1970, S. 235; vgl. aber kritisch W. Stegmüller: Hauptströmungen der Gegenwartsphilosophie. Eine kritische Einführung. Bd III, Stuttgart ${ }^{8} 1987$, S. 279-330.

7 Vgl. bes. C. W. Cassinelli: Total Revolution. A Comparative Study of Germany under Hitler, the Soviet Union under Stalin, and China under Mao. Santa Barbara/Oxford 1976 (= Studies in Comparative Politics. Bd 10.), S. 13-76 u. $225 \mathrm{ff}$

8 Ich kann mich hier auf den vorzüglichen Aufsatz von V. Hentschel: Wirtschafts- und sozialhistorische Brüche und Kontinuitäten zwischen Weimarer Republik und Drittem Reich. In: Zeitschrift für Unternehmensgeschichte 28 (1983), S. 39-80, stützen.

9 S. P. Huntington: Political Order in Changing Societies. New Haven/London 1968, S. 264 u. 266 (meine Übers.). Das Kapitel ist in deutscher Übers. erschienen als: Modernisierung durch Revolution. In: Empirische Revolutionsforschung. Hrsg. von K. v. Beyme. Opladen 1973 (= Probleme der Politik.), S. 92-104; vgl. dazu E. Zimmermann: Krisen, Staatsstreiche und Revolutionen. Theorien, Daten und neuere Forschungsansätze. Opladen 1981 (= Studien zur Sozialwissenschaft. Bd 47.), S. 141-143.

10 W. L. Bühl: Revolution und Systemtransformation. In: Politische Vierteljahresschrift 28 (1987), S. $169 \mathrm{f}$. Wie beliebig die zu überprüfenden Indikatoren sein dürfen, müßte gewiß ausführlicher diskutiert werden (vgl. ebd., S. 179 f.).

11 H. Möller: Die nationalsozialistische Machtergreifung. Konterrevolution oder Revolution? In: Vierteljahrshefte für Zeitgeschichte (VfZG) 31 (1983), S. 25-51, überarb. und erg. Fassung: Die nationalsozialistische Machtergreifung - eine Revolution? In: Machtverfall und Machtergreifung. Aufstieg und Herrschaft des Nationalsozialismus. Hrsg. von R. Lill und H. Oberreuter. München 1983 (= Bayerische Landeszentrale für politische Bildungsarbeit. D 21.), S. 121-139 (ich zitiere im folgenden die VfZG-Fassung) und ders.: Das Ende der Weimarer Demokratie und die nationalsozialistische Revolution von 1933. In: Das Dritte Reich. Herrschaftsstruktur und Geschichte. Hrsg. von M. Broszat und H. Möller. München 1983, S. 9-37 und 275. Ähnlich schon - hätte Möller sich nicht in Berlin habilitiert - könnte man fast eine bayerische Sicht der Dinge vermuten: K. L. Ay: Die deutsche Revolution 1914-1948. Bemerkungen über gesellschaftlichen Wandel und Epochenbegriff. In: Zeitschrift für bayerische Landesgeschichte 36 (1973), S. 877-896.

12 Letzteres offenbar getreu seinem Lehrer Ernst Nolte. Vgl. Der Faschismus in seiner Epoche. Die Action Française. Der italienische Faschismus. Der Nationalsozialismus. München 1963 u. ö., z. B. S. 469 über Gott, Segen und Opfer, S. 412 f. über O. Straßer. Bei Möller: Die nationalsozialistische Machtergreifung (wie Anm. 11), S. 38-43. Die Sicht ist auch bei H. Arendt: Über die Revolution. München 963, zu finden; kurz und treffend dazu Bühl (wie Anm. 10), S. 169.

13 W. P. Adams: Republikanische Verfassung und bürgerliche Freiheit. Die Verfassungen und politischen Ideen der amerikanischen Revolution. Darmstadt/Neuwied 1973 (= Politica. Bd 37.), Vorwort, S. 7.

14 Möller: Die nationalsozialistische Machtergreifung (wie Anm. 11), S. 49 f.

15 So deutlich ders.: Das Ende der Weimarer Demokratie (wie Anm. 11), S. 29.

16 Ebd., S. 29 f. und ders.: Die nationalsozialistische Machtergreifung (wie Anm. 11), S. 50.

17 Th. Schieder: Theorie der Revolution. In: Sowjetsystem und demokratische Gesellschaft. Eine vergleichende Enzyklopädie. Hrsg. von C. D. Kernig. Freiburg i. Br. u. a. Bd V. 1972, Sp. 692-721, auch in: Revolution und Gesellschaft. Theorie und Praxis der Systemveränderung. Hrsg. von Th. Schieder. Freiburg i. Br. u. a. 1973, hier bes. S. 18 f., 21 f. und 27.

18 Möller: Die nationalsozialistische Machtergreifung (wie Anm. 11), S. 26.

19 Ebd., S. 29-42. Vgl. dazu die sicher etwas einseitige Einstufung als Trieb- und Verschwörungstheorien durch Bühl (wie Anm. 10), S. 163 f. Womöglich sollte so der klassische Historiker-Vorwurf wie seinerzeit gegenüber K. D. Bracher vermieden werden: W. Conze: Die politischen Entscheidungen in Deutschland 1929-1933. In: Die Staats- und Wirtschaftskrise des Deutschen Reiches 1929/33. Hrsg. von W. Conze und H. Raupach. Stuttgart 1967 (= Industrielle Welt. Bd 8.), S. 183, Fn. 8. Siehe Anm. 150 unten.

20 Zur Illegalität der "Machtergreifung» schon E. Schaefer: Zur Legalität der nationalsozialistischen >Machtergreifung<. In: Geschichte in Wissenschaft und Unterricht (GWU) 17 (1966), S. 536- 554; K. D. Bracher: Stufen der Machtergreifung. In: Bracher/G. Schulz/W. Sauer: Die nationalsozialistische Machtergreifung. Studien zur Errichtung des totalitären Herrschaftssystems in Deutschland 
1933/34. Bd I. Taschenbuch-Ausgabe. Frankfurt/M./Berlin/Wien 1974 (1. Aufl. 1960), S. 119-236 und ders.: Die deutsche Diktatur. Entstehung, Struktur, Folgen des Nationalsozialismus. Köln/Berlin 1969 u. ö., S. 209-218. Möller: Die nationalsozialistische Machtergreifung (wie Anm. 11), S. 47 ff. Auch Thamer (wie Anm. 1) behandelt die nationalsozialistische Revolution unter diesem Aspekt, nennt die Sache aber richtig "eine gewaltige Veränderung in den politischen und administrativen Führungsgruppen« (S. 258 ff., Zitat S. 266).

21 Möller: Die nationalsozialistische Machtergreifung (wie Anm. 11), S. 44.

22 Die offensichtlichen Schwierigkeiten mit den Eckdaten vgl. ebd., S. 37, Fn. 35 und S. 44 f.; die Fehlinterpretation langfristiger Wandlungsprozesse ebd., S. 47 und 50.

23 Ebd., S. 49.

24 R. Koselleck: Historische Kriterien des neuzeitlichen Revolutionsbegriffs (1968). In: Ders.: Vergangene Zukunft. Zur Semantik geschichtlicher Zeiten (Theorie). Frankfurt/M. 1979, S. 69, 79 f. und E. Zimmermann (wie Anm. 9).

25 Bühl (wie Anm.10), S. 179-182 und 189 f. Es gehört eine kleine Portion Phantasie dazu, sich eine pluralistisch organisierte Gesellschaft samt Systemfunktionen in Form eines verbeulten Kartons vorzustellen.

26 R. Löwenthal: Die nationalsozialistische »Machtergreifung - eine Revolution? Ihr Platz unter den totalitären Revolutionen unseres Jahrhunderts. In: Deutschlands Weg in die Diktatur. Internationale Konferenz zur nationalsozialistischen Machtübernahme im Reichstagsgebäude zu Berlin. Hrsg. von M. Broszat u. a. Berlin 1983, S. 60 ff. Vgl. auch E. Noltes frühe Version: Deutschland und der Kalte Krieg. München/Zürich 1974, überarb. 2. Aufl. Stuttgart 1985, S. 81-89; zur rassistischen neuen Ordnung bereits Cassinelli (wie Anm. 7), S. 45-61.

27 E. Nolte: Europäische Revolutionen des 20. Jahrhunderts. Die nationalsozialistische Machtergreifung im historischen Zusammenhang. In: Die nationalsozialistische Machtergreifung. Hrsg. von W. Michalka. Paderborn u. a. 1984, s. 395-410. Vgl. das mit E. Weber: Revolution? Counterrevolution? What Revolution? In: Journal of Contemporary History 9, 2 (1974), S. 3-47, wieder in: Fascism. A Reader's Guide. Analyses, Interpretations, Bibliography. Hrsg. von W. Laqueur. Berkeley/ Los Angeles 1976, hier bes. S. 435-441. Mit dem Mythos-Nachweis in bezug auf konventionelle Revolutions-Ansichten ist der revolutionäre Charakter der NS-Herrschaft noch nicht nachgewiesen.

28 K. D. Bracher: Revolutionen einst und jetzt (1986). In: Ders.: Die totalitäre Erfahrung. München/ Zürich 1987, S. 31. Vgl. früher G. L. Weinberg: The Foreign Policy of Hitler's Germany: Diplomatic Revolution in Europe 1933-36. Chicago/London 1970, dass.: Starting World War II 1937-1939. Chicago/London 1980; ders.: Deutschlands Wille zum Krieg. Die internationalen Beziehungen 1937-1939. In: Sommer 1939. Die Großmächte und der Europäische Krieg. Hrsg. von W. Benz und H. Graml. Stuttgart 1979 (= Schriftenreihe der Vierteljahrshefte für Zeitgeschichte. Sondernr.), S. 15-32, sowie Arbeiten von H. A. Jacobsen: z. B. Zur Struktur der NS-Außenpolitik 1933-1945. In: Hitler, Deutschland und die Mächte. Materialien zur Außenpolitik des Dritten Reiches. Hrsg. von M. Funke. Düsseldorf 1976 (= Bonner Schriften zur Politik und Zeitgeschichte. Bd 12.), S. 137-185, und A. Hillgruber: Kontinuität und Diskontinuität in der deutschen Außenpolitik von Bismarck bis Hitler. Düsseldorf 1969; ders.: Grundzüge der nationalsozialistischen Außenpolitik 1933-1945. In: Saeculum 24 (1973), S. 328-345, deutlicher K. Hildebrand: Deutsche Außenpolitik 1933-1945. Kalkül oder Dogma? Stuttgart 1971 u. ö., ders.: Hitlers Ort in der Geschichte des preußisch-deutschen Nationalstaates. In: HZ 217 (1973), S. 548-632, im Zusammenhang interpretierend Bracher: Tradition und Revolution (wie Anm. 5), S. 74.

29 J. Goebbels: Vom Kaiserhof zur Reichskanzlei. Eine historische Darstellung in Tagebuchblättern. (Vom 1. Januar 1932 bis zum 1. Mai 1933). München ${ }^{18} 1937$, Eintragungen vom 15. 2., 8. 3., 13. 3., 6. 4. und 18. 4. 1933, S. 263, 277, 281 f., 294 und 300.

30 Hentschel (wie Anm. 8), S. 39. Unter dem Strich ließe sich möglicherweise dasselbe Phänomen beobachten, das seinerzeit in der Entwicklung der Totalitarismus-Theorie diagnostiziert werden konnte: die fast unmerkliche Verwandlung eines analytisch sinnvollen idealtypischen Modells in einen bzw. mehrere Realtypen; vgl. U. D. Adam: Anmerkungen zu methodologischen Fragen in den Sozialwissenschaften: Das Beispiel Faschismus und Totalitarismus. In: Politische Vierteljahresschrift XVI (1975), S. 55-88, wieder in Totalitarismus. Ein Studien-Reader zur Herrschaftsanalyse moderner Diktaturen. Hrsg. von M. Funke. Düsseldorf 1978 (= Bonner Schriften zur Politik und Zeitgeschichte. Bd 14.), S. 13-48.

31 T. Nipperdey: Probleme der Modernisierung in Deutschland. In: Saeculum 30 (1979), S. 292 f., wieder in: Ders.: Nachdenken über die deutsche Geschichte. Essays. München 1986, dort S. 44 f. (Im folgenden wird nach der Saeculum-Fassung zitiert.)

32 Insbesondere S. N. Eisenstadt: Tradition, Wandel und Modernität. Frankfurt/M. 1979 (am. 1973), S. 81-101. Vgl. aber auch R. Bendix: Tradition and Modernity Reconsidered. In: Comparative Studies in Society and History IX, 1966-1967, S. 292-346, einführend am besten H. U. Wehler: Modernisierungstheorie und Geschichte. Göttingen 1975, bes. S. 34-50.

33 E. K. Scheuch unter Mitarbeit von H. D. Klingemann: Theorie des Rechtsradikalismus in westlichen Industriegesellschaften. In: Hamburger Jahrbuch für Wirtschafts- und Gesellschaftspolitik 12 (1967), S. 11-29. 
34 R. Dahrendorf: Demokratie und Sozialstruktur in Deutschland. In: Archives européennes de sociologie I (1960), S. 86-120, den älteren Ansatz von T. Parsons ausführend: Democracy and Social Structure in Pre-Nazi Germany. In: The Journal of Legal and Political Sociology I (1942), S. 96-114, dt. Übersetzung: Demokratie und Sozialstruktur vor der Zeit des Nationalsozialismus. In: Ders.: Beiträge zur soziologischen Theorie. Hrsg. von D. Rüschemeyer. Neuwied/Berlin 1964 Darmstadt/Neuwied 1973 (= Soziologische Texte. Bd 15.), S. 256-281. Dahrendorfs Aufsatz wurde wieder gedruckt in: Ders.: Gesellschaft und Freiheit. Zur soziologischen Analyse der Gegenwart. München 1961, S. 260-299 und 430-433 (ich zitiere im folgenden den Erstdruck). R. Dahrendorf: Gesellschaft und Demokratie in Deutschland. München 1965 (bis vor ca. vier Jahren auch als Taschenbuch, München 1971 u. ö.).

35 Vgl. nur H. U. Wehler: Das Deutsche Kaiserreich 1871-1918. Göttingen 1973 (= Deutsche Geschichte. Hrsg. von J. Leuschner. Bd 9.), sowie die Kritik daran von T. Nipperdey: Wehlers "Kaiserreich«. Eine kritische Auseinandersetzung. In: Geschichte und Gesellschaft 1 (1975), S. 539-560, erw. in: Ders.: Gesellschaft, Kultur, Theorie. Gesammelte Aufsätze zur neueren Geschichte. Göttingen 1976 (= Kritische Studien zur Geschichtswissenschaft. Bd 18.), S. 360-389 und 465; H. G. Zmarzlik: Das Kaiserreich in neuer Sicht? In: HZ 222 (1976), S. 105-126, darauf H.-U. Wehler: Kritik und kritische Antikritik. Ebd., 225 (1977), S. 347-384, wieder in: Ders.: Krisenherde des Kaiserreichs 1871-1918. Studien zur deutschen Sozial- und Verfassungsgeschichte. Göttingen ${ }^{2} 1979$, S. 404-426 und 537-545. Danach der notwendige aber überzogene Rundumschlag von D. Blackbourn/G. Eley: Mythen deutscher Geschichtsschreibung. Die gescheiterte bürgerliche Revolution von 1848. Frankfurt/M./Berlin/Wien 1980 (= Sozialgeschichtliche Bibliothek). Da meine Besprechung des Büchleins für Das Argument m. W. nicht gedruckt wurde vgl. die mit meinen Ansichten nahezu übereinstimmende Rezension von D. Langewiesche: In: HZ 234 (1982), S. 211-213, und ders.: Enthmythologisierung des »deutschen Sonderweges oder auf dem Wege zu neuen Mythen? In: Archiv für Sozialgeschichte XXI, 1981, S. 527-532.

36 Dahrendorf: Demokratie und Sozialstruktur (wie Anm. 34), S. 109

37 Ders.: Gesellschaft und Demokratie (wie Anm. 34), S. 401. Vgl. auch die Rezensionen anläßlich der amerikanischen Übersetzung des Buches 1967: G. D. Feldman: In; Journal of Social History 2, 1968-1969, S. 273-277; P. N. Stearns: In: Central European History I (1968), S. 175-181 und Ch. S. Maier: In: History \& Theory VIII, 1969, S. 119-133, allesamt mit dem Tenor: anregend, aber nicht erschöpfend. Vgl. auch J. A. Hall: Diagnoses of Our Time. Six Views of Our Social Condition. London u. a. 1981, S. 120-156, bes. 132 f. und $145 \mathrm{ff}$.

38 B. Moore, Jr.: Social Origins of Dictatorship and Democracy. Lord and Peasant in the Making of the Modern World. Boston 1966, im folgenden zit. nach der dt. Übers.: Soziale Ursprünge von Diktatur und Demokratie. Die Rolle der Grundbesitzer und Bauern bei der Entstehung der modernen Welt. Frankfurt/M. 1969. Taschenbuch-Ausg. 1974 u. ö. Vgl. zur Einführung in die Kritik J. M. Wiener. In: History \& Theory XV, 1976, S. 146-175 und die wichtige Besprechung von R. P. Dore: Making Sense of History. In: Archives européennes de sociologie X (1969), S. 295-305.

39 Moore: Soziale Ursprünge (wie Anm. 38), S. 24, 56-60, 338 und 499 f.

40 Ebd., S. 512-516. Vgl. auch den Überblick bei Kocka: Ursprünge (wie Anm. 6).

41 Moore: Soziale Ursprünge (wie Anm. 38), S. 515.

42 Ebd., S. 338.

43 Vgl. dazu W. Sauer: National Socialism. Totalitarianism or Fascism? In: The American Historical Review LXXIII, 1967/68, S. 404-424, bes. S. $412 \mathrm{ff}$.

44 Vgl. Nipperdey: 1933 (wie Anm. 6), Neudruck, S. 383 f., und ders.: Probleme (wie Anm. 31), bes. S. 296-300. Siehe auch Anm. 35 oben und den in Anm. 146 zitierten Aufsatz von Wehler.

$45 \mathrm{Vgl}$. dazu besonders die prägnanten Aufsätze von H. Mommsen: Zur Verschränkung traditioneller und faschistischer Führungsgruppen in Deutschland beim Übergang von der Bewegungs- zur Systemphase. In: Faschismus als soziale Bewegung. Deutschland und Italien im Vergleich. Hrsg. von W. Schieder. Hamburg 1976 (= Historische Perspektiven. Bd 3.), S. 157-191; ders.: Die deutschen Eliten und der Mythos des nationalen Aufbruchs von 1933. In: Merkur 423, 38 (1984), S. 97-102 und ders.: Die nationalsozialistische Machtergreifung und die deutsche Gesellschaft. In : Die nationalsozialistische Machtergreifung (wie Anm. 27), S. 29-46.

46 Nipperdey: Probleme (wie Anm. 31), S. 23. Wehler: Modernisierungstheorie (wie Anm. 32), plädiert etwas umständlich dafür, die Interdependenz der disparaten Faktoren durch Bindung an die Durchsetzung der Industrialisierung »historisch auf[zu]laden« (S. 42).

47 H. Kaelble: Der Mythos von der rapiden Industrialisierung in Deutschland. In: Geschichte und Gesellschaft 9 (1983), S. 106-118. Einen breiter angelegten Vergleich hat schon, fast ein Jahrzehnt früher, P. Graf v. Kielmansegg angeregt: Hitler und die deutsche Revolution. In: Merkur 317, 28 (1974), S. 922-936, wieder in: Ders.: Nachdenken über die Demokratie. Aufsätze aus einem unruhigen Jahrzehnt. Stuttgart 1980, hier S. 197.

48 Vgl. Nipperdey: Probleme (wie Anm. 31), S. 296 ff., Neudruck S. 49 ff.

49 F. Borkenau: Zur Soziologie des Faschismus. In: Archiv für Sozialwissenschaft und Sozialpolitik 68(1933), S. 513-547, hier und im folgenden zitiert nach dem Wiederabdruck in: Theorien über den Faschismus. Hrsg. von E. Nolte. Köln/Berlin 1967 (= Neue Wissenschaftliche Bibliothek. Bd 21.), S. $179 \mathrm{f}$. 
51 Vgl. die Rezensionen von J. Habermas: Die verzögerte Moderne. In: Der Spiegel Nr. 53, 29. Jg., 29.12.1965, S. 87 f., zuletzt wieder in: Ders.: Philosophisch-politische Profile. Frankfurt/M., ${ }^{3} 1981$, S. 453-457 und vor allem F. Fürstenberg. In: Zeitschrift für Politik N.F. XIII, 1966, S. 367-371. Das Dahrendorf zentrale Problem der Eliten (Gesellschaft und Demokratie [wie Anm. 34], S. 243-324), erschien als Vorabdruck (der S. 293-307) unter dem Titel: Das Kartell der Angst. In: Merkur 210, XIX. Jg., 1965, S. 803-815, in Auseinandersetzung mit W. Zapf: Wandlungen der deutschen Elite. Ein Zirkulationsmodell deutscher Führungsgruppen 1919-1961. München 1965. ${ }^{2} 1966$ ( = Studien zur Soziologie. Bd 2.). Dieses Problembewußtsein war schulebildend.

52 Siehe nur K. v. Klemperer: Glaube, Religion, Kirche und der deutsche Widerstand gegen den $\mathrm{Na}$ tionalsozialismus. In: VfZG 28 (1980), S. 293-309, wieder in: Widerstand im Dritten Reich. Probleme, Ereignisse, Gestalten. Hrsg. von H. Graml. Frankfurt/M. 1984, S. 140-156 und 258-260; R. J. Evans: German Women and the Triumph of Hitler. In: The Journal of Modern History 48, H. 1, Suppl., 1976, S. 163 f.; jetzt wieder L. Gellot/M. Phayer: Dissenting Voices: Catholic Women in Opposition to Fascism. In: Journal of Contemporary History 22 (1987), S. 91-114.

53 Dahrendorf: Gesellschaft und Demokratie (wie Anm. 34), S. 440. Vgl. dazu R. Eilers: Die nationalsozialistische Schulpolitik. Eine Studie zur Funktion der Erziehung im totalitären Staat. Köln/Opladen 1963 (= Staat und Politik. Bd 4.); M. H. Kater: Hitlerjugend und Schule im Dritten Reich. In: HZ 228 (1979), S. 572-623; D. Orlow: Die Adolf-Hitler-Schulen: In: VfZG 13 (1965), S. 272-284; Elite für die Diktatur. Die Nationalpolitischen Erziehungsanstalten 1933-1945. Ein Dokumentarbericht. Hrsg. von H. Ueberhorst. Düsseldorf 1969; H. Scholtz: Die NS-Ordensburgen. In: VfZG 15(1967), S. 269-298 und ders.: NS-Ausleseschulen. Internatsschulen als Herrschaftsmittel des Führerstaates. Göttingen 1973. W. Struve: Elites against Democracy. Leadership Ideals in Bourgeois Political Thought in Germany, 1890-1933. Princeton, N. J. 1973, S. 448-453, hat Material zusammengestellt, das auf eindeutige Überrepräsentation der oberen Mittelschichten in den NS-Ausleseschulen hindeutet, und äußert Zweifel an ihrer Fähigkeit zur Vermittlung von Elitequalifikationen.

54 D. Orlow: The History of the Nazi Party: 1933-1945. Pittsburgh 1973, S. 348, und im Anschluß daran W. J. Jannen, Jr.: National Socialists and Social Mobility. In: Journal of Social History 9 (1975-1976), S. 350.

55 Vgl. zusätzlich zur in Anm. 53 zitierten Literatur: E. Nyssen: Schule im Nationalsozialismus. Heidelberg 1979; O. Ottweiler: Die nationalsozialistische Schulpolitik im Bereich des Volksschulwesens im Reich. In: Erziehung und Schulung im Dritten Reich. Hrsg. von M. Heinemann. T. 1. Stuttgart 1980 (= Veröffentlichungen der Historischen Kommission der Deutschen Gesellschaft für Erziehungswissenschaft. Bd 4,1.), S. 193-215; B. Zymek: War die nationalsozialistische Schulpolitik sozialrevolutionär? Praxis und Theorie der Auslese im Schulwesen während der nationalsozialistischen Herrschaft in Deutschland. Ebd., S. 264-274; A. Klönne: Jugend im Dritten Reich. Die Hitler-Jugend und ihre Gegner. Dokumente und Analysen. Düsseldorf: Köln 1982, S. 286-288; neuerdings H. Scholtz: Erziehung und Unterricht unterm Hakenkreuz. Göttingen 1985, bes. S. 163-167.

56 Dahrendorf: Gesellschaft und Demokratie (wie Anm. 34), S. 435. Vgl. dazu nur A. Schweitzer: Big Business in the Third Reich. Bloomington 1964, S. 239-296 und 410 ff.; H.-E. Volkmann: Zum Verhältnis von Großwirtschaft und NS-Regime im Zweiten Weltkrieg. In: Zweiter Weltkrieg und sozialer Wandel. Achsenmächte und besetzte Länder. Hrsg. von W. Długoborski. Göttingen 1981 (= Kritische Studien zur Geschichtswissenschaft. Bd 47.), S. 87-116. Hentschel (wie Anm. 8), S. 43 und 46, vgl. dagegen F. Blaich: Die bayerische Industrie 1933-1939. Elemente von Gleichschaltung, Konformismus und Selbstbehauptung. In: Bayern in der NZ-Zeit. Bd II: Herrschaft und Gesellschaft im Konflikt. T. A. Hrsg. von M. Broszat/E. Fröhlich. München/Wien 1979, S. 237-280.

57 Vgl. H. Buchheim: Die SS - das Herrschaftsinstrument. In: Ders.: u.a.: Anatomie des SS-Staates. Bd I (Gutachten des Instituts für Zeitgeschichte). Taschenbuch-Ausgabe München 1967 (zuerst 1965), S. 19-24.

58 Vgl. W. Sauer: Die Mobilmachung der Gewalt. In: Bracher/Schulz/Sauer (wie Anm. 20), Bd III, S. $276 \mathrm{ff}$.

59 Dahrendorf: Gesellschaft und Demokratie (wie Anm. 34), S. 436. Letzteres hätte schon F. L. Neumann: Behemoth. The Structure and Practice of National Socialism. New York 1942, erw. 1944, entnommen werden können.

60 Es lohnt leider kaum, auf die sowjet- wie auch die neomarxistische Kritik einzugehen; als repräsentativ ist die Lektüre von G. Lozek/R. Richter: Zur Auseinandersetzung mit vorherrschenden bürgerlichen Faschismustheorien. In: Faschismusforschung. Positionen - Probleme - Polemik. Hrsg von D. Eichholtz/K. Gossweiler. Berlin (Ost) 1980, S. 417-451, erweiterte Fassung: Legende oder Rechtfertigung? Zur Kritik der Faschismustheorien in der bürgerlichen Geschichtsschreibung. Berlin (Ost) 1980 (= Zur Kritik der bürgerlichen Ideologie. Bd 97.), bes. S. 26-38 und 51-60 zu empfehlen. Vgl. auch G. Lozek: Grundfragen der aktuellen Auseinandersetzung mit der bürgerlichen Historiographie. In: Beiträge zur Geschichte der Arbeiterbewegung 22(1980), S. 20-35 und G. Rose: Modernisierungstheorien und bürgerliche Sozialwissenschaften. In: Zeitschrift für Geschichtswissenschaft 29(1981), S. 5-21. Neomarxistisch: J. B. Müller: Kommunismus und Nationalsozialismus. Ein sozioökonomischer Vergleich. In: M. Greiffenhagen u.a.: Totalitarismus. Zur 
Problematik eines politischen Begriffs. München 1972, S. 61-96 und 134-140, bes. S. 94 ff.; E. Hennig: Thesen zur deutschen Sozial- und Wirtschaftsgeschichte 1933 bis 1938. Frankfurt/M. 1973 (= ed. Suhrkamp. 662.), S. 24-37; in zunehmender "Linientreue« R. Kühnl: Faschismustheorien. Texte zur Faschismusdiskussion 2. Ein Leitfaden. Reinbek bei Hamburg 1979, S. 152-167.

61 D. Schoenbaum: Class and Status in the Third Reich. D. phil. thesis (MS). University of Oxford 1964, mit anspruchsvollerem Titel veröffentlicht: Hitler's Social Revolution. Class and Status in Nazi Germany 1933-1939. Garden City, N.Y. 1966 und London 1966, im folgenden zitiert nach der deutschen Übersetzung: Die braune Revolution. Eine Sozialgeschichte des Dritten Reiches. Köln/Berlin 1968. 2. Aufl. mit einem Nachwort von H. Mommsen. Köln 1980, zugleich als Taschenbuch, München 1980.

62 Gregor Straßer wäre dann einer der wichtigsten NS-Revolutionstheoretiker; vgl. ders.: Ziele und Wege. In: Nationalsozialistische Briefe, Juli 1927, gekürzt abgedruckt bei R. Kühnl: Die nationalsozialistische Linke 1925-1930. Meisenheim am Glan 1966 (= Marburger Abhandlungen zur Politischen Wissenschaft. Bd 6.), S. 283-287, dazu K.-P. Hoepke: Die deutsche Rechte und der italienische Faschismus. Ein Beitrag zum Selbstverständnis und zur Politik von Gruppen und Verbänden der deutschen Rechte. Düsseldorf 1968 (= Beiträge zur Geschichte des Parlamentarismus und der politischen Parteien. Bd 38.), S. 198, und B. Miller Lane: Nazi Ideology: Some Unfinished Business. In: Central European History VII, 1974, S. 19-24. Schoenbaum: Die braune Revolution (wie Anm. 61), S. 107 und 81-101. Mit R. Zitelmann: Hitler. Selbstverständnis eines Revolutionärs. Leamington Spa/Hamburg/New York 1987, liegt nun eine detaillierte Darstellung von Hitlers Revolutionsverständnis vor, die hier nicht mehr berücksichtigt werden konnte, am Bild der NSHerrschaft auch wenig ändert; vgl. die Zusammenfassung von G. Schreiber: Hitler. Interpretationen 1923-1983. Ergebnisse, Methoden und Probleme der Forschung. Darmstadt 1984, S. 247-263.

63 Schoenbaum: Die braune Revolution (wie Anm. 61), S. 26. Ähnlich später H. A. Turner, Jr.: Fascism and Modernization. In: World Politics XXXIV, 1971-1972, S. 547-564, zugleich deutsch: Faschismus und Anti-Modernismus. In: Ders.: Faschismus und Kapitalismus in Deutschland. Studien zum Verhältnis zwischen Nationalsozialismus und Wirtschaft. Göttingen 1972, S. 157-182. Turners Feststellung, modernisierende Maßnahmen des Nationalsozialismus seien Mittel zu einem ganz anderen (antimodernen) Ziel gewesen, das, sobald erreicht, dieselben Maßnahmen "zum großen Teil unnötig machen« würde (deutsche Fassung S. 172), bewegt sich im Bereich der reinen Spekulation. Diese ist hochgradig unrealistisch, denn wie hätte ein de-industrialisiertes und de-technisiertes deutsches Kernreich sein Ostimperium und anderes wohl beherrschen sollen? Für als Wehrbauern exportierte Facharbeiter schlecht oder überhaupt nicht ausgebildete Heloten aus dem Osten zu importieren, wäre auf die Dauer wohl auch keine Lösung gewesen. Diese letzten Geheimnisse lüftet auch Zitelmanns Hitler-Studie (Anm. 62), nicht.

64 Alles bei Schoenbaum: Die braune Revolution (wie Anm. 61), S. 348.

65 Ebd., S. 365.

66 Zuletzt von Hentschel (wie Anm. 8), S. 39, Fn. 2.

67 Schoenbaum: Die braune Revolution (wie Anm. 61), S. 89.

68 Ebd., S. 334

69 Ähnlich W. Schlau: Die blockierte Mobilität. Zum sozialökonomischen Hintergrund der Katastrophe. In: Die Deutsche Neurose. Über die beschädigte Identität der Deutschen. Frankfurt/M., Berlin, Wien 1980 (= Schriften der Carl Friedrich von Siemens Stiftung. Bd 3.), S. 189, der von wfiktiven Aufstiegschancen« im Parteiapparat spricht, insgesamt pessimistischer H. Kaelble: Sozialer Aufstieg in den USA und Deutschland, 1900-1960. In: Sozialgeschichte Heute. Festschrift für Hans Rosenberg. Hrsg. von H.-U. Wehler. Göttingen 1974 (= Kritische Studien zur Geschichtswissenschaft. Bd 11.), bes. S. 537. f.; ders.: Soziale Mobilität in Deutschland, 1900-1960. In: Ders. u.a.: Probleme der Modernisierung in Deutschland. Sozialhistorische Studien zum 19. und 20. Jahrhundert. Opladen 1978 ( = Schriften des Zentralinstituts für sozialwissenschaftliche Forschung der FU Berlin. Bd 27.), S. 235-327, wieder in: Ders.: Soziale Mobilität und Chancengleichheit im 19. und 20. Jahrhundert. Deutschland im internationalen Vergleich. Göttingen 1983 (= Kritische Studien zur Geschichtswissenschaft. Bd 55.), S. 59-127 und 269-293, sowie Hentschel (wie Anm. 8), S. $78 \mathrm{f}$.

70 J. C. Fest: Hitler. Eine Biographie. Frankfurt/M./Berlin/Wien 1973 u.ö. in div. Ausgaben, Zitat S. 513. Vgl. dazu H. Graml: Probleme einer Hitler-Biographie. In: VfZG 22 (1974), S. 76-92, und die Rezension von A. Hillgruber: In: HZ 219 (1974), S. 161-165. Graml, so wird deutlich, hat das Buch gelesen, während viele andere ihr Entzücken oder Mißfallen über die These äußerten, ohne das Publikum darauf hinzuweisen, daß die 21 Jahre ältere Biographie A. Bullocks nüchterner und gleichzeitig zuverlässiger ist.

71 Fest (wie Anm. 70), S. 1035 f. Sobald Fest zu den Inhalten kommt, fällt auf, daß es sich dabei weder um Neues, noch um Unverwechselbares handelt (vgl. z.B. S. 1031).

72 Die einschlägigen Arbeiten von $\mathrm{H}$. Mommsen werden nicht, eine von M. Broszat nicht unbedingt der dort enthaltenen Informationen wegen rezipiert (vgl. S. 652 und Anm. 196, S. 1110), keiner von beiden darf etwas zur $Z$ wischenbetrachtung, S. 511-529, beisteuern, die auch entsprechend ausfällt. 
73 J. P. Stern: Hitler: Der Führer und das Volk, München/Wien 1978 (engl. 1975), S. 161. Das Buch ist auch als Taschenbuch (München 1981) erschienen.

74 Ebd., S. 159. Vgl. D. Bald: Von der Wehrmacht zur Bundeswehr. Kontinuität und Neubeginn. In: Sozialgeschichte der Bundesrepublik Deutschland. Beiträge zum Kontinuitätsproblem. Hrsg. von W. Conze/M. R. Lepsius. Stuttgart 1983 (= Industrielle Welt. Bd 34.), S. 401, Fn. 40 mit weiterführender Literatur.

75 Schoenbaum: Die braune Revolution (wie Anm. 61), S. 96, richtig seltsamerweise im nächsten Kapitel, S. 148 f. Vgl. J. Kocka/M. Prinz: Vom "neuen Mittelstand « zum angestellten Arbeitnehmer. Kontinuität und Wandel der deutschen Angestellten seit der Weimarer Republik. In: Sozialgeschichte der Bundesrepublik Deutschland (wie Anm. 74), S. 223 f., und Prinz (wie Anm. 2).

76 Vgl. R. Stumpf: Die Wehrmacht-Elite. Rang- und Herkunftsstruktur der deutschen Generale und Admirale 1933-1945. Boppard am Rhein 1982 (= Wehrwissenschaftliche Forschung. Abt. Militärgeschichtliche Studien. Bd 29.), S. 344 f.

77 Bald (wie Anm. 74), S. 398-402 und Tabelle 2, S. 407.

78 Vgl. Dahrendorf: Demokratie und Sozialstruktur (wie Anm. 34), S. 114 f., wieder Nolte (wie Anm. 27), S. 407.

79 Vgl. Schoenbaum: Die braune Revolution (wie Anm. 61), S. 226-241, mit D. Winkler: Frauenarbeit im "Dritten Reich«. Hamburg 1977 (= Historische Perspektiven. Bd 9.) A. Tröger: Die Frau im wesensgemäßen Einsatz. In: Frauengruppe Faschismusforschung. Mutterkreuz und Arbeitsbuch. Zur Geschichte der Frauen in der Weimarer Republik und im Nationalsozialismus. Frankfurt/M. 1981, S. 246-272 und 357-363, und D. Peukert: Volksgenossen und Gemeinschaftsfremde. Anpassung, Ausmerze und Aufbegehren unter dem Nationalsozialismus. Köln 1982, S. 210-212.

80 D. Klinksiek: Die Frau im NS-Staat. Stuttgart 1982 (= Schriftenreihe der Vierteljahrshefte für Zeitgeschichte. Nr. 44.), vgl. dazu die Rezension von D. Winkler. In: HZ 237, 1983, S. 750 f.

81 Vgl. nur T. W. Mason: Zur Entstehung des Gesetzes zur Ordnung der nationalen Arbeit, vom 20. Januar 1934: Ein Versuch über das Verhältnis »archaischer« und »moderner« Momente in der neuesten deutschen Geschichte. In: Industrielles System und politische Entwicklung in der Weimarer Republik. Hrsg. von H. Mommsen/D. Petzina/B. Weisbrod. Düsseldorf 1974, S. 322-351, und Ch. S. Maier: Between Taylorism and Technocracy: European Ideologies and the Vision of Industrial Productivity in the 1920s. In: Journal of Contemporary History 5, 2 (1970), S. 27-61, gek. deutsche Übersetzung in: Die Weimarer Republik (wie Anm. 6), S. 188-213 und jetzt M. Broszat: Zur Struktur der NS-Massenbewegung. In: VfZG 31 (1983), S. 52-76, bes. S. 67.

82 Vgl. grundsätzlich W. Fischer / P. Czada: Wandlungen in der deutschen Industriestruktur im 20. Jahrhundert. Ein statistisch-deskriptiver Ansatz. In: Entstehung und Wandel der modernen Gesellschaft. Festschrift für H. Rosenberg zum 65. Geburtstag. Hrsg. von G. A. Ritter. Berlin 1970, S. 144-155, und H. Pohl: Die Konzentration in der deutschen Wirtschaft vom ausgehenden 19. Jahrhundert bis 1945. In: Die Konzentration in der deutschen Wirtschaft seit dem 19. Jahrhundert. Hrsg. von H. Pohl / W. Treue. Wiesbaden 1978 (= Zeitschrift für Unternehmensgeschichte. Beiheft 11.), S. 29. ff., speziell D. Swatek: Unternehmenskonzentration als Ergebnis und Mittel nationalsozialistischer Wirtschaftspolitik. Berlin 1972 (=Volkswirtschaftliche Schriften. H. 181.); G. Janssen: Das Ministerium Speer. Deutschlands Rüstung im Krieg. Berlin/Frankfurt/M./Wien 1968, sowie die Tabelle bei W. Fischer: Bergbau, Industrie und Handwerk 1914-1970. In: Handbuch der deutschen Wirtschafts- und Sozialgeschichte. Hrsg. von W. Zorn. Bd 2. Stuttgart 1976, S. 811, und Hentschel (wie Anm. 8), S. 43-46.

93 Die Antitrustgesetzgebung in den USA geht auf das Sherman-Gesetz von 1890 zurück. Zur deutschen Kartellgesetzgebung nach $1945 \mathrm{vgl}$. P. Hüttenberger: Wirtschaftsordnung und Interessenpolitik in der Kartellgesetzgebung der Bundesrepublik 1949-1957. In: VfZG 24(1976), S. 287-307, allgemein auch M. J. Piore / Ch. F. Sabel: Das Ende der Massenproduktion. Studie über die Requalifizierung der Arbeit und die Rückkehr der Ökonomie in der Gesellschaft. Berlin 1985 (am., unter weit weniger akademischem Titel, 1984), S. 38 ff.

94 Italiener sprechen übrigens im Angesicht ihrer eigenen turmbewehrten Monumentalbauten aus den frühen 40er Jahren gern vom »germanischen Stil» (so jedenfalls Giovanni Agnelli).

Bs Alles nach B. Miller Lane: Architecture and Politics in Germany. 1918-1945. Cambridge. Mass. 1968, S. 185-204.

86 Vgl. L. Suhling: Deutsche Baukunst. Technologie und Ideologie im Industriebau des »Dritten Reiches«. In: Naturwissenschaft, Technik und NS-Ideologie. Beiträge zur Wissenschaftsgeschichte des Dritten Reichs. Hrsg. von H. Mehrtens und S. Richter. Frankfurt/M. 1980, S. 272 ff.

87 Miller Lane: Architecture (wie Anm. 85), S. 205-210. Ein Gegenbeispiel ist die "Purifizierung“ des Kurhauses in Bad Schwalbach in den 30er Jahren. Die dekorativen Bauglieder des 1874-1878/79 in neubarockem Stil erbauten Hauses wurden abgeschlagen, was in etwa dem Zurückstutzen eines überladenen Palastes auf bürgerliches Normalmaß gleichkommt; vgl. T. Föhl. In: Kurstädte in Deutschland. Zur Geschichte einer Baugattung. Hrsg. von R. Bothe. Berlin 1984, S. 74-78.

${ }_{88}$ M.-L. Recker: Die Großstadt als Wohn- und Lebensbereich im Nationalsozialismus. Zur Gründung der "Stadt des KdF-Wagens". Frankfurt/M., New York 1981 (= Wolfsburger Beiträge zur Stadtgeschichte und Stadtentwicklung.), ergänzend dazu E. Forndran: Die Stadt- und Industrie- 
gründungen Wolfsburg und Salzgitter. Entscheidungsprozesse im nationalsozialistischen Herrschaftssystem. Frankfurt/M., New York 1984 (= Wolfsburger Beiträge zur Stadtgeschichte und Stadtentwicklung).

89 Suhling (wie Anm. 86) und H. Henselmann / H. Hentrich / W. Wortmann: "Architekten sind keine Kinder von Niederlagen, aber im tiefsten Ernst haben wir in unseren Herzen Gräber, wo wir vieles vergraben und versteckt halten«. In: Bauwelt 48, 75. Jg./Stadtbauwelt 84 (1984), S. 2054/350-2081/377; W. Durth: Der programmierte Wiederaufbau. Speers "Arbeitsstab zum Wiederaufbau bombenzerstörter Städte», ebd., S. 2082/378-2094/390 und ders.: Deutsche Architekten. Biographische Verflechtungen 199-1970. Braunschweig/Wiesbaden 1986 (= Schriften des Deutschen Architekturmuseums zur Architekturgeschichte und Architekturtheorie.). Ich verdanke den Hinweis hierauf Herrn Dipl.-Ing. T. Rinderspacher, Darmstadt.

90 Vgl. R. P. Sieferle: Fortschrittsfeinde? Opposition gegen Technik und Industrie von der Romantik bis zur Gegenwart. München 1984 (= Die Sozialverträglichkeit von Energiesystemen. Bd 5.), S. 219 f., und K.-H. Ludwig: Technik und Ingenieure im Dritten Reich. Düsseldorf 1974, S. 335-341.

91 Sieferle (wie Anm. 90), S. 221, zum gesamten Komplex Ludwig (wie Anm. 90). Ludwigs Studie ist von L. Burchardt in MGM 20 (1976), S. 192-194 besprochen worden, ansonsten in keiner der führenden allgemeinen oder wirtschafts- und sozialhistorischen Fachzeitschriften.

92 Eisenstadt (wie Anm. 32) und ders.: Revolution und die Transformation von Gesellschaften. Eine vergleichende Untersuchung verschiedener Kulturen. Opladen 1982 (am. 1978), vgl. dazu auch J. A. Goldstone: Theories of Revolution: The Third Generation. In: World Politics XXXII (1979-1980), bes. S. 445-447. Die vorangegangenen Generationen wurden besprochen von $L$. Stone: Theories of Revolution. Ebd., XVIII (1965-1966), S. 159-176, aktualisierte Fassung (engl. 1972) in deutscher Übersetzung: Revolutionstheorien. In: Ders.: Ursachen der Englischen Revolution 1529-1642. Frankfurt/M./Berlin/Wien 1983 (= Sozialgeschichtliche Bibliothek.), S. 13-40.

93 Zum Problem der abnehmenden Akzeptanz "gleichgeschalteter« Medien bes. E. Martens: Zum Beispiel »Das Reich«. Zur Phänomenologie der Presse im totalitären Regime. Köln 1972; über den Rundfunk jetzt A. Diller: Rundfunkpolitik im Dritten Reich. München 1980 (= Rundfunk in Deutschland. Hrsg. von H. Bausch. Bd 2.)

94 Vgl. H. D. Schäfer: Das gespaltene Bewußtsein. Über die Lebenswirklichkeit in Deutschland 1933-1945. In: Ders.: Das gespaltene Bewußtsein. Über deutsche Kultur und Lebenswirklichkeit 1933-1945. München/Wien 1981, S. 114-162 und 230-243, dazu ausführlich M. H. Kater: Die Sozialgeschichte und das Dritte Reich. Überlegungen zu neuen Büchern. In: Archiv für Sozialgeschichte XXII (1982), S. 665-671. Daß die Konsumgesellschaft nicht im Aufschwung begriffen war, hebt zuletzt Hentschel (wie Anm. 8), S. 59, hervor.

95 Zuletzt H. Möller: Exodus der Kultur. Schriftsteller, Wissenschaftler und Künstler in der Emigration nach 1933. München 1984, S. 31-38.

96 Schon Schoenbaum: Die braune Revolution (wie Anm. 61), S. 145.

97 H. Spode: "Der deutsche Arbeiter reist«. Massentourismus im Dritten Reich. In: Sozialgeschichte der Freizeit. Untersuchungen zum Wandel der Alltagskultur in Deutschland. Hrsg. von G. Huck. Wuppertal 1980, S. 281-306, ders.: Arbeiterurlaub im Dritten Reich. In: C. Sachse u.a.: Angst, Belohnung, Zucht und Ordnung. Herrschaftsmechanismen im Nationalsozialismus. Opladen 1982 (= Schriften des Zentralinstituts für sozialwissenschaftliche Forschung der FU Berlin. Bd 41.), S. 275-328. Vgl. ebenfalls die saloppe Bemerkung von O. Meissner: Staatssekretär unter EbertHindenburg-Hitler. Der Schicksalsweg des deutschen Volkes von 1918-1945, wie ich ihn erlebte. Hamburg 1950, S. 332.

98 Vgl. J. v. Kruedener: Zielkonflikt in der nationalsozialistischen Agrarpolitik. Ein Beitrag zur Diskussion des Leistungsproblems in zentral gelenkten Wirtschaftssystemen. In: Zeitschrift für Wirtschafts- und Sozialwissenschaften 94 (1974), S. 335-361; Hentschel (wie Anm. 8), S. $72-75$ mit weiterer Literatur und H. Priebe: Die subventionierte Unvernunft. Landwirtschaft und Naturhaushalt. Berlin 1985, S. 51-55.

99 E. Fröhlich: Die Partei auf lokaler Ebene. Zwischen gesellschaftlicher Assimilation und Veränderungsdynamik. In: Der »Führerstaat«. Mythos und Realität. Studien zur Struktur und Politik des Dritten Reiches. Hrsg. von G. Hirschfeld / L. Kettenacker. Stuttgart 1981 (= Veröffentlichungen des Deutschen Historischen Instituts London. Bd 8.), S. 265-268. Zweifel an der Modernität des HJ-Modells einer Jugendkultur hat Klönne: Jugend im Dritten Reich (wie Anm. 55), S. 287 f.

100 Eine Geschichte des Benimms und der Etikette vom Kaiserreich bis in die Bundesrepublik ist $\mathrm{m}$. W. noch nicht geschrieben worden. Übergenau und mit nur unter größten Schwierigkeiten zu erschlieBenden Ergebnissen H.-V. Krumrey: Entwicklungsstrukturen von Verhaltensstandarden. Eine soziologische Prozeßanalyse auf der Grundlage deutscher Anstands- und Manierenbücher von 1870 bis 1970. Frankfurt/M. 1984, etwas impressionistisch H. Glaser: Kulturgeschichte der Bundesrepublik Deutschland. Bd 2: Zwischen Grundgesetz und Großer Koalition 1949-1967. München/ Wien 1986, vgl. dort S. 98-129 u. ö.

101 Borkenau: Zur Soziologie des Faschismus (wie Anm. 49), S. 178. Die These wird nachhaltig von Gregor (siehe unten Anm. 126 und 128) vertreten.

${ }_{102}$ Die m. E. plausiblere Gegenposition vertritt M. R. Lepsius: Demokratie in Deutschland als historisch-soziologisches Problem. In: Spätkapitalismus oder Industriegesellschaft? Verhandlungen des 
16. Deutschen Soziologentages. Hrsg. von T. W. Adorno. Stuttgart 1969, S. 197-214, neuerdings etwas unsystematisch, streckenweise aber durchaus einleuchtend J. A. Hall: Powers and Liberties. The Causes and Consequences of the Rise of the West. Oxford 1985; Harmondsworth 1986, S. $145-188$ und $215 \mathrm{ff}$.

103 Borkenau: Zur Soziologie des Faschismus (wie Anm. 49), S. 172-178; vgl. zur Rolle der Arbeiterklasse bes. ebd., S. 161, zur Scheidung der Begriffe Diktatur und Demokratie S. 157 f. Inzwischen zwingen uns nicht nur Entwicklungen in Ländern der sogenannten Dritten Welt, den früher anzunehmenden zwingenden oder wenigstens bedingenden Zusammenhang von industriell-technologischer und demokratischer, rechtsstaatlicher, partizipatorischer, sozialstaatlicher Entwicklung pessimistischer zu beurteilen. Visionen einer Zweiteilung der Gesellschaft in sozusagen Flüssige und Überflüssige mit dann notwendig zunehmenden autoritären und repressiven Herrschaftsformen sind nicht aus der Luft gegriffen, den Verteidigern des Erreichten im politischen Raum stehen Entwicklungen im industriellen Bereich nicht notwendig hilfreich zur Seite.

104 Vgl. den Literaturbericht von M. Vaudagna: Structural Change in Fascist Italy. In: Journal of Economic History XXXVIII (1978), S. 184-192.

105 E. F. Damascelli: La "Restaurazione antifascista liberista«. Ristago e sviluppo economico il fascismo. In: Il Movimento di Liberazione in Italia 104, 23 (1971), S. 47-70, wieder in: Il regime fascista. Hrsg. von A. Aquarone / M. Vernassa. Bologna 1974 (= Problemi e prospettive: Serie di storia.), S. 281-305.

$106 \mathrm{Vgl}$. dazu auch M. F. Neufeld: Italy: School for Awekening Countries. The Italian Labor Movement and Its Political, Social, and Economic Setting from 1800 to 1960. Ithaca, N. Y. 1961 (= Cornell Industrial and Labor Relations Reports. Nr. 5.)

107 G. Toniolo: L'economia dell'Italia fascista. Rom/Bari 1980, S. 197-268. Vgl. auch L'economica italiana nel periodo fascista. Hrsg. von P. Ciocca / G. Toniolo. Bologna 1976 (= Problemi e prospettive: Serie di storia.)

108 Vgl. R. Lill: Geschichte Italiens vom 16. Jahrhundert bis zu den Anfängen des Faschismus. Darmstadt 1980, S. 243 ff., und V. Sellin: Die Anfänge staatlicher Sozialreform im liberalen Italien. Stuttgart 1971 (= Industrielle Welt. Bd 13.); ders.: Kapitalismus und Organisation. Beobachtungen an der Industrialisierung Italiens. In: Organisierter Kapitalismus. Voraussetzungen und Anfänge. Hrsg. von H. A. Winkler. Göttingen 1974 (= Kritische Studien zur Geschichtswissenschaft. Bd 9.), S. 84-100. Für die Nachkriegszeit A. Shonfield: Modern Capitalism. The Changing Balance of Public and Private Power. London u. a. 1965, in der deutschen Übersetzung: Geplanter Kapitalismus. Wirtschaftspolitik in Westeuropa und den USA. Köln/Berlin 1968, S. 209 ff.

109 Ch. S. Maier: Some Recent Studies of Fascism. In: Journal of Modern History 48 (1976), S. 520 f.

110 A. F. K. Organski: Fascism and Modernization. In: The Nature of Fascism. Hrsg. von S. J. Woolf. London 1968 (= Reading University Studies on Contemporary Europe: Studies in Fascism. Bd II.), S. 19-41 und G. Germani: Fascism and Class. Ebd., S. 65-96.

111 Germani (wie Anm. 110), S. 86-90 und Organski (wie Anm. 110), S. 22 und 25. Eine Distributionskrise nimmt »die« Modernisierungstheorie gewöhnlich an letzter Stelle, nach der Identitätskrise, der Legitimitätskrise, der Penetrationskrise, der Partizipationskrise und der Integrationskrise an, die allesamt im Verlauf der Nationsbildung zu bewältigen sind. Über die Reihenfolge herrscht allerdings durchaus keine Klarheit, sicher ist lediglich, daß nicht mehrere zugleich hereinbrechen dürfen.

112 Organski (wie Anm. 110), S. 28 f., Zitat S. 28. Wichtig in diesem Zusammenhang die Bemerkungen von S. L. Andreski: Some Soziological Considerations on Fascism and Class. In: The Nature of Fascism (wie Anm. 110), S. 97-103, der lieber von Freisetzung als von Mobilisierung reden möchte (S. 97) und vor allem die Notwendigkeit einer erschreckten Oberschicht betont (S. 99). Vgl. das auch bei Moore (wie Anm. 38), zu Italien S. 501 und 517 f., allgemein S. 497-519.

113 Organski (wie Anm. 110), S. 20 und 31. Soziale Mobilisierung habe, wie auch die ökonomische Mobilisierungsrate, abgenommen.

114 P. Graf v. Kielmansegg: Die demokratische Revolution und die Spielräume politischen Handelns. In: Merkur 414, 36 (1982), S. 1159, vollständige Fassung in: HZ 137 (1983), S. 529-558.

115 Cassels: Janus: The Two Faces of Fascism (1969). In: Reappraisals of Fascism. Hrsg. von H. A. Turner, Jr. New York 1975 (= Modern Scholarship in European History.), bes. S. 78 und 85 f.

116 Vgl. ebd., S. 73 ff.

117 T. Rafalski: Italienischer Faschismus in der Weltwirtschaftskrise (1925-1936). Wirtschaft, Gesellschaft und Politik auf der Schwelle zur Moderne. Opladen 1984 (= Schriften des Zentralinstituts für sozialwissenschaftliche Forschung der FU Berlin. Bd 45.), S. 339 ff. Vgl. auch P. C. MayerTasch: Korporativismus und Autoritarismus. Eine Studie zu Theorie und Praxis der berufsständischen Rechts- und Staatsidee. Frankfurt/M. 1971, bes. S. 229-237.

118 Verbände und Staat. Vom Pluralismus zum Korporatismus. Analysen, Positionen, Dokumente. Hrsg. von U. v. Alemann / R. G. Heinze. Opladen 1979, ${ }^{2} 1981$; R. G. Heinze: Verbändepolitik und "Neokorporatismus«. Zur politischen Soziologie organisierter Interessen. Mit einem Vorwort von C. Offe. Opladen 1981 (= Studien zur Sozialwissenschaft. Bd 46.), und Geschichte und Gesellschaft 10 (1984), H. 2: Kapitalismus, Korporatismus, Keynesianismus. Hrsg. von H.-J. Puhle, S. $163-259$. 
119 Tannenbaum: The Goals of Italian Fascism. In: The American Historical Review LXXIV (1968/69), S. 1183-1204.

120 Ebd., S. 1185, 1204. Eine revidierte Fassung des Aufsatzes ist in: Ders.: The Fascist Experience. Italian Society and Culture 1922-1945. New York/London 1972, S. 43-55, zu finden, wo es heißt, der Faschismus endete dann doch als Konterrevolution (S. 54). Die Ursache der Akzentverschiebung war nicht zu ermitteln.

121 Tannenbaum (wie Anm. 119), S. 1196 f. Vgl. dagegen Rafalski (wie Anm. 117), S. 391-413.

122 Sarti: Fascist Modernization in Italy: Traditional or Revolutionary? In: The American Historical Review LXXV (1969/70), S. 1183-1204, italienische Übersetzung: La modernizzazione fascista in Italia: conservatrice o rivoluzionaria? In: Il regime fascista (wie Anm. 105), S. 259-278; Maier: Between Taylorism and Technocracy (wie Anm. 81).

123 Sarti: Fascist Modernization (wie Anm. 122), S. 1037 ff., 1043. Die Kritik von A. Hughes / M. Kolinsky: "Paradigmatic Fascism" and Modernization: A Critique. In: Political Studies XXIV (1976), S. 380 f., scheint hier etwas überzogen. Zum Produktivismus siehe auch H.-U. Thamer: Faschismus und italienische Gesellschaft. In: Ders. und W. Wippermann: Faschistische und neofaschistische Bewegungen. Probleme empirischer Faschismusforschung. Darmstadt 1977 (= Erträge der Forschung. Bd 72.), S. 184-1 86. Die bisher angeführten Autoren untersuchen das Problem der sozialen Revolution, wogegen mehrere Referenten des Kolloquiums des Instituts für Zeitgeschichte: Der italienische Faschismus. Probleme und Forschungstendenzen. München/Wien 1983, eine politische Revolution betonen; J. Petersen, S. 28-30, R. Vivarelli, S. 51-54, und W. Schieder, etwas sibyllinisch, S. 61, und S. 91-93. Petersen geht allerdings nicht darauf ein, wieweit die von ihm hervorgehobene faschistische Elite das Regime überdauerte.

124 Maier: Between Taylorism and Technocracy (wie Anm. 81), S. 43; die entsprechende amerikanische Version wird als Flucht vor der Akzeptanz von Klassenkonflikten und sozialer Ungleichheit beschrieben (S. 29).

125 Vgl. Mayer-Tasch (wie Anm. 117), S. 139 f.

126 Gregor: The Ideology of Fascism. The Rationale of Totalitarianism. New York/London 1969; ders.: Fascism and Modernization: Some Addenda. In: World Politics XXVI (1973-1974), S. 370-384 (eine Entgegnung auf Ashby [wie Anm. 63]); ders.: Interpretations of Fascism. Morristown, N. J. 1974, S. 171-212; ders.: The Fascist Persuasion in Radical Politics. Princeton, N.Y. 1974; ders.: Young Mussolini and the Intellectual Origins of Fascism. Berkeley/Los Angeles/London 1979.

127 Vgl. Hughes / Kolinsky (wie Anm. 123), S. 377-380.

128 Gregor: Italian Fascism and Developmental Dictatorship. Princeton, N. J. 1979, S. 172-206. Vgl. dazu schon Neufeld (wie Anm. 106), für Deutschland Hentschel (wie Anm. 8), der einen revolutionären Bruch der Sozialbeziehungen durch die Ausschaltung der Gewerkschaften herbeigeführt sieht, weniger durch diejenige der Betriebsräte (S. 70 f.), aber keinen Zusammenhang zwischen beidem herzustellen sucht.

129 Cannistraro: Mussolini's Cultural Revolution. Fascist or Nationalist? In: Journal of Contemporary History 7, H. 3-4, 1972, S. 115-139. Vgl. auch ders.: The Organization of Totalitarian Culture: Cultural Policy and the Mass Media in Fascist Italy, 1922-1945. Ph. D. Diss.. New York University 1971; ders.: La fabrica del consenso. Fascismo e mass media. Prefazione die Renzo De Felice. Rom/Bari 1975 (= Tempo nuovi. Bd 74.); ders.: The Radio in Fascist Italy. In: Journal of European Studies 2 (1972), S. 127-154.

130 Cannistraro: Mussolini's Cultural Revolution (wie Anm. 129), S. 120, 137. Tannenbaum: The Fascist Experience (wie Anm. 120), S. 333, bezeichnet den Grad kultureller Mobilität - was immer das bedeuten mag, und Tannenbaum wertet sie auch als "politisch bedeutungslos" - als eines der wichtigsten Erbstücke des Faschismus.

131 R. De. Felice: Der Faschismus. Ein Interview von M. A. Ledeen. Stuttgart 1977 (ital. 1975), S. 55-67, Zitat S. 39. Dazu jetzt auch V. de Grazia: The Culture of Consent. Mass Organization of Leisure in Fascist Italy. Cambridge u. a. 1981 (= Columbia University-Diss. 1976.)

132 G. A. Craig: Geschichte Europas im 19. und 20. Jahrhundert. Bd 2. München 1979 (am. 1961 u. ö., 1974), S. 87. Etwas unentschlossen in der Sache ist M. Wolffsohn: Linker und rechter National-Sozialismus. In: Zeitschrift für Politik N. F. XXIV (1977), S. 58, 79.

133 Vgl. H. Lübbe: Was heißt: „Das kann man nur historisch erklären?« In: Geschichte - Ereignis und Erzählung. Hrsg. von R. Koselleck / W.-D. Stempel. München 1973 (= Poetik und Hermeneutik. Bd V.), S. 542-554, wieder in: Theorieprobleme der Geschichtswissenschaft. Hrsg. von Th. Schieder / K. Gräubig. Darmstadt 1977 (= Wege der Forschung. Bd CCCLXXVIII.), S. 148-163.

134 Zuletzt R. Bendix: Freiheit und historisches Schicksal. Heidelberger Max Weber-Vorlesungen 1981. Frankfurt/M. 1981, S. 19-20 u. ö.; vgl. auch W. Wippermann: Faschismustheorien. Zum Stand der gegenwärtigen Diskussion. Darmstadt, 2. verb. Aufl. 1975 (= Erträge der Forschung. Bd 17.), S. 95 ff., und Wehler: Modernisierungstheorie (wie Anm. 32), S. $11 \mathrm{ff}$.

135 Vgl. etwa G. G. Iggers: The Idea of Progress: A Critical Reassessment. In: The American Historical Review LXXI (1965/66), S. 1-17; G. Masur: Distinctive Traits of Western Civilization: Through the Eyes of Western Historians. Ebd. LXVII (1961/62), S. 591-608; S. Pollard: The Idea of Progress. History and Society. London 1968 (= The New Thinker's Library.); R. A. Nisbet: History of the Idea of Progress, Revolution, and Freedom. In: Ethics LXXII (1961/62), deutsche Überset- 
zung: Über Fortschritt, Revolution und Freiheit. In: Ders.: Zur Geschichte der politischen Gewalt. Drei Studien. Frankfurt/M. 1966 (= ed. suhrkamp. 187.), S. 7-29; R. Koselleck: Fortschritt. In: Geschichtliche Grundbegriffe. Historisches Lexikon zur politisch-soziologischen Sprache in Deutschland. Hrsg. von O. Brunner / W. Conze / R. Koselleck. Bd 2. Stuttgart 1975, S. 351-423.

136 F. Hölderlin: Die Bücher der Zeiten. In: Ders.: Sämtliche Werke und Briefe. Hrsg. von G. Mieth. Bd 1. München 1970, S. 70; Über das Gesetz der Freiheit (1974). Ebd., S. 836.

137 H. V. Treitschke: Deutsche Geschichte im Neunzehnten Jahrhundert. III. Teil. Neudruck Leipzig 1928, S. VIII.

138 Bezogen auf J. Ritter: Hegel und die französische Revolution. Frankfurt/M. 1965 (zuerst 1957) (= ed. suhrkamp. 114.); P. Bertaux: Hölderlin und die Französische Revolution. Frankfurt/M. 1969 (= ed. suhrkamp. 344.) Vgl. auch S. Avinieri: Hegels Theorie des modernen Staates. Frankfurt/M. 1976 (engl. 1972), S. 262-280; Ch. Taylor: Hegel. Frankfurt/M. 1978 (engl. 1975), S. 509-560, und B. Groethuysen: Philosophie der Französischen Revolution. Neuwied/Berlin 1971 (frz. 1956) (= Politica. Bd 32.), S. 125 ff., sowie K. Löwith: Weltgeschichte und Heilgeschehen. Die theologischen Voraussetzungen der Geschichtsphilosophie. Stuttgart 1953 u. ö. (zuerst am. 1949).

139 Die einleuchtende Datierung umwälzender Ereignisse auf 1945 ff. bei Bracher: Tradition und Revolution (wie Anm. 5), bes. S. 77 f., und Winkler: Vom Mythos (wie Anm. 5), S. 489 f.

140 Die erstgenannte Sicht bei M. Broszat: Soziale Motivation und Führer-Bindung des Nationalsozialismus. In: VfZG 18 (1970), S. 392-409 und H. Mommsen: Ausnahmezustand als Herrschaftstechnik des NS-Regimes. In: Hitler, Deutschland und die Mächte (wie Anm. 28), S. 30-45, die zweite bei K. Hildebrand: Hitlers "Programm« und seine Realisierung 1939-1942 (frz. 1971). Ebd., S. 63-93 und E. Jäckel: Hitlers Weltanschauung. Entwurf einer Herrschaft. Tübingen 1969, erweiterte und überarbeitete Neuausgabe Stuttgart 1981; ders.: Hitlers Herrschaft. Vollzug einer Weltanschauung. Stutgart 1986. Jäckel nimmt in der fortlaufenden Debatte als spezialisierter HitlerForscher eine Sonderstellung ein, die Positionen der übrigen Teilnehmer lassen sich auf ihre entweder innen- oder außenpolitischen Forschungstätigkeiten zurückführen.

141 Vgl. L. Herbst: Der Totale Krieg und die Ordnung der Wirtschaft. Die Kriegswirtschaft im Spannungsfeld von Politik, Ideologie und Propaganda 1939-1945. Stuttgart 1982 (= Studien zur Zeitgeschichte. Bd 21.), S. 276-313 und 433-452.

142 W. Windelband: Lehrbuch der Geschichte der Philosophie. Hrsg. von H. Heimsoeth. Tübingen ${ }^{15} 1957$ (1. Aufl. 1891), \$31.7-11, S. 355-365, Zitat S. 356.

${ }^{143}$ J. Kocka: Vorindustrielle Faktoren in der deutschen Industrialisierung. Industriebürokratie und »neuer Mittelstand «. In: Das kaiserliche Deutschland. Politik und Gesellschaft 1870-1918. Hrsg. von M. Stürmer. Düsseldorf 1970, S. 265-286.

144 G. G. Iggers: Deutsche Geschichtswissenschaft. Eine Kritik der traditionellen Geschichtsauffassung von Herder bis zur Gegenwart. München 1971. Erw. 2. Aufl. 1972 (am. 1968), S. 385; vgl. auch H. Albert: Geschichte und Gesetz. Zur Kritik des methodologischen Historismus. In: Sozialphilosophie als Aufklärung. Festschrift für Ernst Topitsch. Hrsg. von K. Salamun. Tübingen 1979.

145 Vgl. H.-U. Wehlers Sammlung: Historische Sozialwissenschaft und Geschichtsschreibung. Studien zu Aufgaben und Traditionen deutscher Geschichtswissenschaft. Göttingen 1980, auch H. Albert (wie Anm. 144), S. 132.

146 H.-U. Wehler: "Deutscher Sonderweg« oder allgemeine Probleme des westlichen Kapitalismus. Zur Kritik an einigen »Mychen deutscher Geschichtsschreibung«. In: Merkur 396, 35 (1981), wieder in: Ders.: Preußen ist wieder chic ... Politik und Polemik in zwanzig Essays. Fankfurt/M. 1983 (= ed. suhrkamp. 1152/NF Bd 152.), Zitat hier S. 30.

147 E. Weber: Revolution? (wie Anm. 27), bes. S. 445, 451-455 und 458-461. Vgl. auch S. G. Payne: Fascism. Comparison and Definition. Madison, Wisconsin/London 1980, S. 96-104, der teilweise auf Bracher: Tradition und Revolution (wie Anm. 5) zurückgreift.

148 Vgl. F. Pingel: Häftlinge unter SS-Herrschaft. Widerstand, Selbstbehauptung und Vernichtung im Konzentrationslager. Hamburg 1978 (= Historische Perspektiven. Bd 12.), S. 118 ff.; U. Herbert: Fremdarbeiter. Politik und Praxis des "Ausländer-Einsatzes in der Kriegswirtschaft des Dritten Reiches. Berlin/Bonn 1985 und ders.: Geschichte der Ausländerbeschäftigung in Deutschland 1880 bis 1980. Saisonarbeiter, Zwangsarbeiter, Gastarbeiter. Hamburg 1985, S. 120 ff. Im Zusammenhang der Judenemanzipation ist der konterrevolutionäre Ideologiegehalt freilich eindeutig.

$149 \mathrm{Vgl}$. zur Verwaltungsgeschichte jetzt die Einleitung von D. Rebentisch / K. Teppe: In: Verwaltung contra Menschenführung im Staat Hitlers. Studien zum politisch-administrativen System. Hrsg. von dens. Göttingen 1986, S. 7-32, und Rebentisch: Innere Verwaltung. In: Deutsche Verwaltungsgeschichte. Hrsg. von K. G. A. Jeserich / H. Pohl / G. Christoph v. Unruh. Bd 4: Das Reich als Republik und in der Zeit des Nationalsozialismus. Stuttgart 1985, S. 732-774. Vergleichend dazu wenigstens über die italienische Richterschaft G. N. Modona: La magistratura e il fascismo. In: Fascismo e societa italiana. Hrsg. von G. Quazza. Turin 1973 (= Piccolo Biblioteca Einaudi: Geografia. Storia. Bd 200.), S. 125-181, dazu die Bemerkungen von Maier: Some Recent Studies (wie Anm. 109), S. $515 \mathrm{f}$.

$150 \mathrm{Vgl}$. Bracher: Revolutionen einst und jetzt (wie Anm. 28), S. 41-43; Koselleck: Historische Kriterien (wie Anm. 24), S. 70-74 und K. Griewank: Der neuzeitliche Revolutionsbegriff. Entstehung und Geschichte. Hrsg. von J. Horn-Staiger. Taschenbuch-Ausgabe. Frankfurt/M. 1973 (zuerst 
1955). Es sollte hier hervorgehoben werden, daß 1933 auch dem heutigen Gebrauch nahekommende Revolutionsbegriffe in der Diskussion waren - neben den von $\mathrm{H}$. Möller zitierten Beispielen (siehe Anm. 19) -, an denen die Geschehnisse gemessen werden könnten; vgl. etwa J. Hashagen: Wie entstehen Revolutionen? In: Zeitwende 8/I (1932), S. 147-151 (Besprechung von: E. Rosenstock: Die europäischen Revolutionen. Volkscharaktere und Staatenbildung. Jena 1931, überarb.: E. Rosenstock-Huessy: Die europäischen Revolutionen und der Charakter der Nationen. Stuttgart/Köln 1951), S. 149 f.: Eine "mit Gewaltmitteln arbeitende plötzlich hervortretende Bewegung zu gründlicher Umgestaltung des Staates und der Gesellschaft, der Wirtschaft und schließlich auch der Kultur eines Gerneinwesens«.

151 L. Krieger: Nazism: Highway or Byway? In: Central European History XI (1978), S. 16, 12. Vgl. auch Broszat: Plädoyer (wie Anm. 2), bes. S. 382, insges. S. 373-385; und ders.: Zur Struktur der NS-Massenbewegung (wie Anm. 81), passim.

152 Vgl. Barrington Moore: Über Fortschritt (wie Anm. 135), S. 8-12 und Anm. 5, S. 28.

$153 \mathrm{Vgl}$. W. G. Runciman: Unnecessary Revolution: The Case of France. In: Archives européennes de sociologie XXIV (1983), S. 291-318. Der Topos einer unvollendeten, neuerdings pessimistischer der gescheiterten Revolution im russischen Fall bei I. Deutscher: The Unfinished Revolution. Russia 1917-1967. London u. a. 1967; A. B. Ulam: Russia's Failed Revolutions. From the Decembrists to the Dissidents. New York 1981; deutsche Übersetzung: Rußlands gescheiterte Revolutionen. Von den Dekabristen zu den Dissidenten, München/Zürich 1985. Niemand ist $\mathrm{m}$.W. bislang auf die Idee gekommen, Hitler ernsthaft mit dem Bild Napoleons I. zu vergleichen, wie G. Levebre: Napoléon. Paris 1935 (= Peuples et civilisations. Histoire générale. Bd XIV.), es entworfen hat: als Bezwinger und Vollstrecker der Revolution zugleich. Expansionskriege sind zwar Expansionskriege, aber der Mord an den europäischen Juden ist kein Äquivalent zum code civil, die SS keines zum Einpflanzen der fundamentalen Prinzipien des modernen Staates und der modernen Gesellschaft wenngleich Führerprinzip und sonderrechtliche Maßnahmen einen vollständigen Bruch mit der europäischen Tradition des Staates darstellten - und trotz Niederlage beider, um zum Anfang zurückzukommen, hinterließ einer von beiden nur ein Mehr an Tod und Zerstörung, womit wir wieder bei Jacob Burckhardts alter Weisheit angelangt wären. 